Accelerator Division

Alternating Gradient Synchrotron Department

BROOKHAVEN NATIONAL LABORATORY

Upton, New York 11973

Accelerator Division

Technical Note

AGS/AD/Tech. Note No. 373

\title{
STUDY OF THE BOOSTER INJECTION AT KEK
}

(A talk given at the AGS Machine Physics Meeting

held on February 5, 1993)

\author{
Yoshihiko Shoji*
}

April 9, 1993

*On leave from KEK. 


\section{Introduction}

First, I wish to thank you for giving me a chance to talk about the KEK Booster. At KEK my duties involve working with the MR magnet and slow extraction. I am sure you may have questions that I will not be able to answer; in those cases, I will contact my colleagues at KEK and answer these questions later.

The AGS and the KEK-PS are similar; they are proton and heavy ion cascade machines although the collider project at KEK is not yet approved, there is $\mathrm{H}^{-}$injection at the Booster (proton).

Today I will talk about the Booster injection of high intensity proton beams. This is one of the most important topics at KEK and also at the AGS.

Tables I and II show normalized emittance blow up at KEK and at the AGS. The emittance blow up at Booster injection stands out in both of the facilities. The experiences at the KEK Booster may be helpful to us at the AGS. Today I present these subjects.

List $i$ lists the content of this talk (Study of Booster Injection at KEK). Some of these studies were not performed by me, so I have listed the main study members for each activity; perhaps you know some of these people. Motohiro Kihara is the head of the KEK-PS Complex. Tadamichi Kawakubo visited BNL for two months last year; he developed the IPM for the KEKPS (we call it NDPM). Hikaru Sato once worked at BNL.

Since these studies were done, I have re-examined or re-analyzed the data. So, in some instances my conclusions are different from the original results.

The subjects as listed are too much to cover in the one hour we have for this meeting, so I will cover the subjects in their order of importance. 
Table I Emittance of proton beam at the KEK-PS

Reported by $T$. Kawakubo [ to be reported in KEK Accelerater Study Note] The emittances in the ring based on the beam profile measured by the NDPM ( the same as the IPM at BNL ).

Accelerator kinetic energy normalized emittance LINAC pulse width ( $95 \% \mathrm{~mm}$ mrad ) horizontal vertical

\begin{tabular}{|c|c|c|c|c|}
\hline LINAC & $40 \mathrm{MeV}$ & 7.4 & 4.5 & 40 \\
\hline \multirow[t]{2}{*}{ BOOSTER } & $40 \mathrm{MeV}$ & $47 / 51$ & $8 / 20$ & $20 / 60$ \\
\hline & $500 \mathrm{MeV}$ & $44 / 57$ & $10 /$ & 160 \\
\hline \multirow[t]{2}{*}{ MR } & $500 \mathrm{MeV}$ & 32 & 12 & 20 \\
\hline & $12 \mathrm{GeV}$ & 50 & 83 & 20 \\
\hline
\end{tabular}

Table II Emittance of proton beam at the AGS Summarized by T. Roser.

Accelerator kinetic energy normalized emittance beam intensity ( $95 \% \mathrm{~mm} \mathrm{mrad}$ ) horizontal vertical ( 10 ppp )

\begin{tabular}{|c|c|c|c|c|c|}
\hline LINAC & 200 & $\mathrm{MeV}$ & 7 & 5 & 3.6 \\
\hline \multirow[t]{2}{*}{ BOOSTER } & 200 & $\mathrm{MeV}$ & 45 & 21 & 3.0 \\
\hline & 1.5 & $\mathrm{GeV}$ & 60 & 40 & 2.0 \\
\hline \multirow[t]{2}{*}{ AGS } & 1.5 & $\mathrm{GeV}$ & 72 & 34 & 1.5 \\
\hline & 30 & $\mathrm{GeV}$ & 125 & 67 & 1.3 \\
\hline
\end{tabular}


LIST $i \quad$ CONTENTS

STUDY OF THE BOOSTER INJECTION AT KEK

$$
Y . S h o j i
$$

1. Introduction to the KEK Booster

KEK-PS complex.

KEK $40 \mathrm{MeV}$ line ( LTB)

KEK 50OMeV Booster

2. Compare KEK-Booster with AGS Booster

Space charge limit

3. Reach to the space charge limit (1987-1989)

N. Kumag̊i

4. Beam size v.s. Beam intensity (1989)

N.Kumagai, Y.Shoji \& K.Marutsuka

5. Transverse matching (1991)

M.Kihara, I.Yamane \& T. Kawakubo

6. Emittance measurement with MWPM (1992)

T.Adachi

7. Fdge focus of the injection Bump magnets(1993)

I. Yamane

8. Injection to MR

- Resonance line $v . s$. Intensity

- Coupled bunch

Y.Shoji, K.Marutsuka, T.Toyama \& H.Sato

9. Miscellaneous 


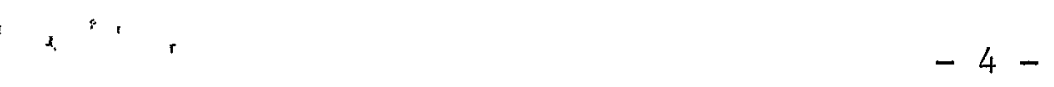

\section{Introduction to the KEK Booster}

Figure 1 shows the KEK proton accelerator complex: $750 \mathrm{keV} \mathrm{CW}, 20 \mathrm{MeV}$ and 40 $\mathrm{MeV}$ Alvarez Linacs, $500 \mathrm{MeV}$ Booster Synchrotron, and the $12 \mathrm{GeV}$ Main Ring (synchrotron). The construction of a heavy ion collider would be at $\mathrm{ECH}(4-7 \mathrm{GeV} / \mathrm{u})$. A big water Cherenkov neutrino detector is going to be built here for the calibration of the KAMIOKANDE detector. The Alvarez Linac is separated into two: $20 \mathrm{MeV}$ and $40 \mathrm{MeV}$. When the MR is accelerating and extracting the proton beam, the Booster supplies high intensity protons for the BSF. The intensity of the MR is much smaller than that for the BSF, because the MR cannot accept high intensity beam now. With the time length of the Linac beam, we control the intensities; normally $20 \mu \mathrm{s}$ for the MR and 60-70 $\mu \mathrm{s}$ for the BSF. The operating cycle is normally 3 weeks (sometimes 4); maintenance is done once every 3 weeks (from Friday morning to Wednesday morning).

Table III shows the PS intensity. This is an example of the proton beam intensity of the KEK-PS. Unfortunately this is not a good sample--I don't remember what was wrong! Normally the Booster intensity is from 1.6 to $2 \times 10^{12} \mathrm{ppp}$. The injection efficiency into the Booster is close to $100 \%$. The injection efficiency into the MR is about $95 \%$.

Figure 2 shows the KEK-Booster and the $40 \mathrm{MeV}$ line. The KEK-Booster is a combined function synchrotron. The size is $1 / 9$ that of the MR ( $37 \mathrm{~m}$ circumference). It accelerates 40 $\mathrm{MeV}$ Linac beam up to $500 \mathrm{MeV}, 50 \mathrm{~ms}$ rapid cycle (injection to extraction $=25 \mathrm{~ms}$ ).

The Linac-to-Booster transport line (we call it the $40 \mathrm{MeV}$ line) consists of three parts: matching section (Q1-Q5), $\pi$-section ( $\operatorname{Pr} 3-\mathrm{B} 1$ ), and $\pi$-phase achromatic section (B1-stripping foil). There are 7 multi-wire profile monitors along the line. This figures also shows the emittance monitor, the front slit, back sense wire and the momentum analyzer. 


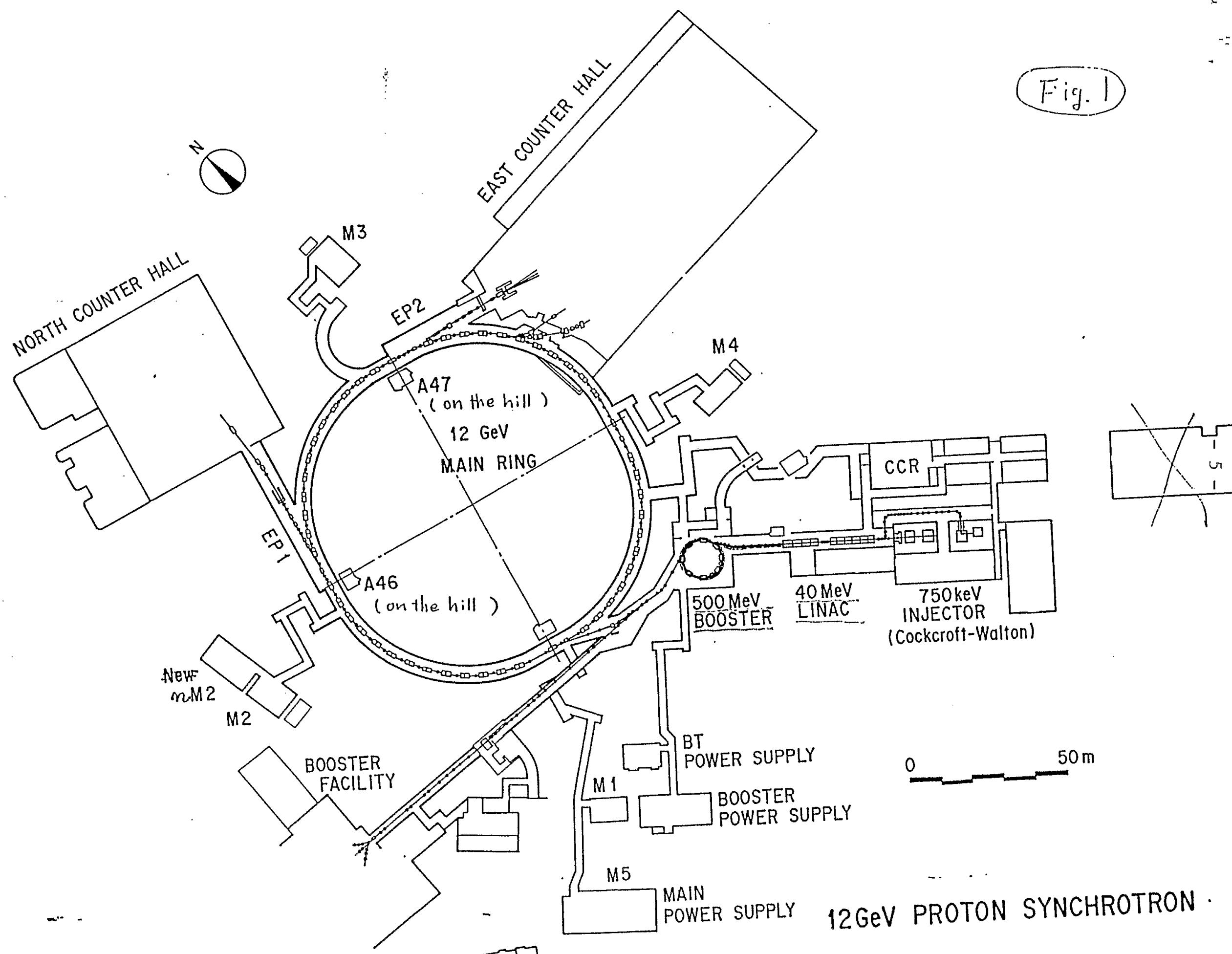


INTENSITY

ITME : $02 / 07 / 92 \quad 14: 33: 17$

$\begin{array}{lll}\mathrm{CH}-2 & =11.5 & \mathrm{~mA} \\ \mathrm{CM}-7 & =9.6 & \mathrm{~mA} \\ 20 \mathrm{MeV} C T . & =5.6 & \mathrm{~mA} \\ 40 \mathrm{MeV} \mathrm{CT}-1 & =5.6 & \mathrm{~mA} \\ 40 \mathrm{MeV} C T-3 & =5.5 & \mathrm{~mA} \\ (\mathrm{CT}-1 / \mathrm{CH}-7) * 100 & =58.3 & \%\end{array}$

<BSF >

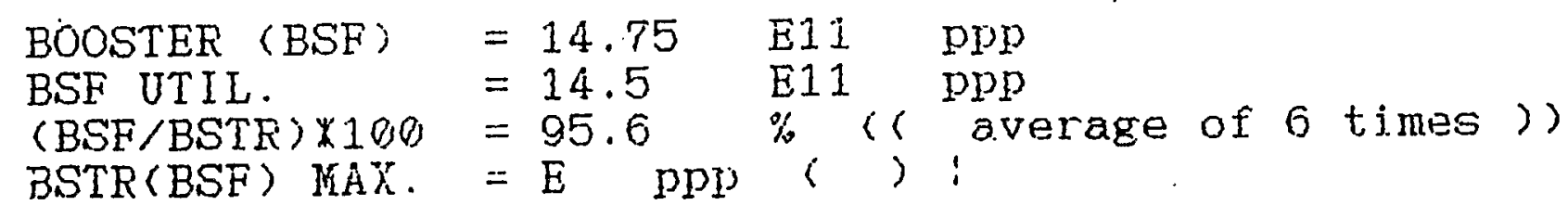

< Main Eing >

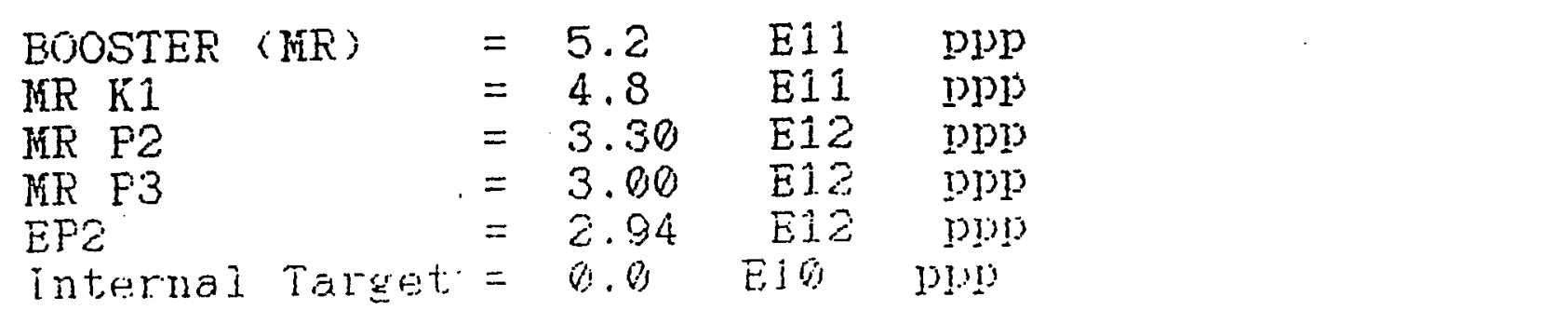




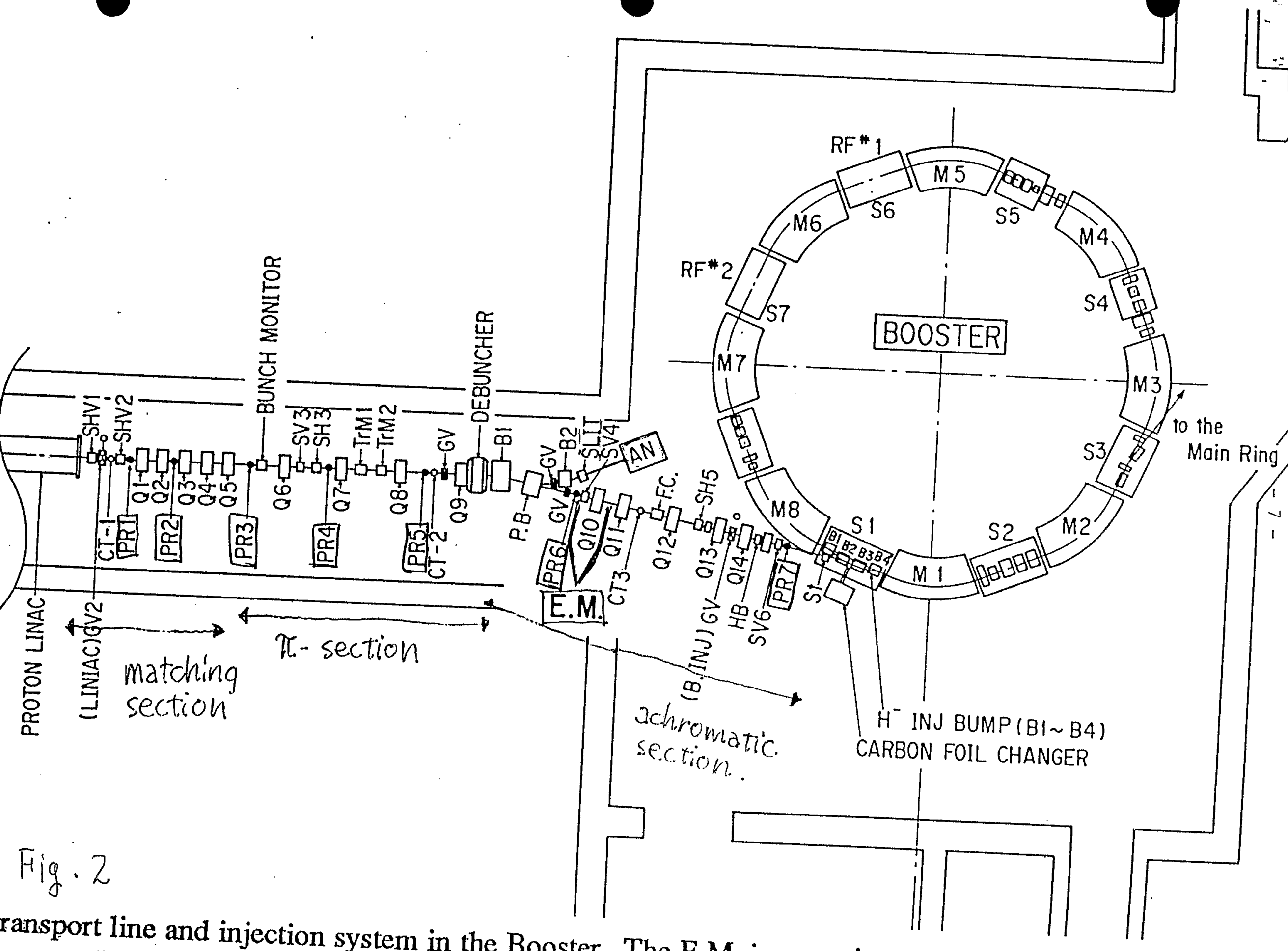

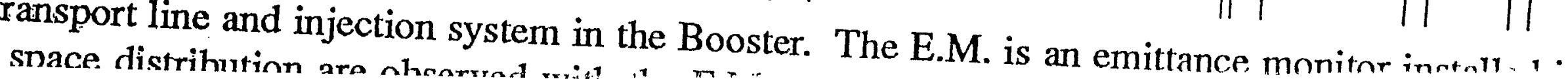


Figure 3 shows $40 \mathrm{MeV}$ profiles. This is an example of the $40 \mathrm{MeV}$ MWPM display of 32 channels (each $2.5 \mathrm{~mm}$ space, $30 \mu \mathrm{m} \mathrm{W}$ wire).

Figure 4 shows the $40 \mathrm{MeV}$ line optics and Figure 5 shows the typical EM results. This is an example of the emittance measured by the EM. The slit at the upstream end and the sensing wire at the downstream end move to make two-dimensional density distribution contours. I have heard that the sensing wire will be replaced by the slit and the Faraday cup. The initial slit width is $0.05 \mathrm{~mm}$ and the thickness is $5 \mu \mathrm{m}$. The second slit width is $0.1 \mathrm{~mm}$, corresponding to $0.13 \mathrm{mrad}$. One line shows the full width contribution of the dispersion at the initial slit. The measurement takes place every Monday morning. The results are plotted like this and posted on the CCR bulletin board. Figure 6 shows the long-term EM stability.

Next is the momentum analyzer consisting of two slits, and the vertical bend and the sensing wires. Figure 7 shows the Someya monitor. The measurement takes place once for every MR cycle $(4 \mathrm{sec})$. The results are displayed on our CRTs and TV monitors.

Figure 8 shows a Someya example. There are three examples. The horizontal full scale is $1.5 \%$ of the momentum spread. The vertical axis is the intensity and the time. The center section is the typical result when the Linac is tuned well. The initial change is due to the slow response of the compensation feedback of the beam loading. Usually the full momentum spread is 0.3 to $0.4 \%$. The real display was more beautiful! 
Fig.3 ZR-4DWE! FFOFILE DIS,LAY

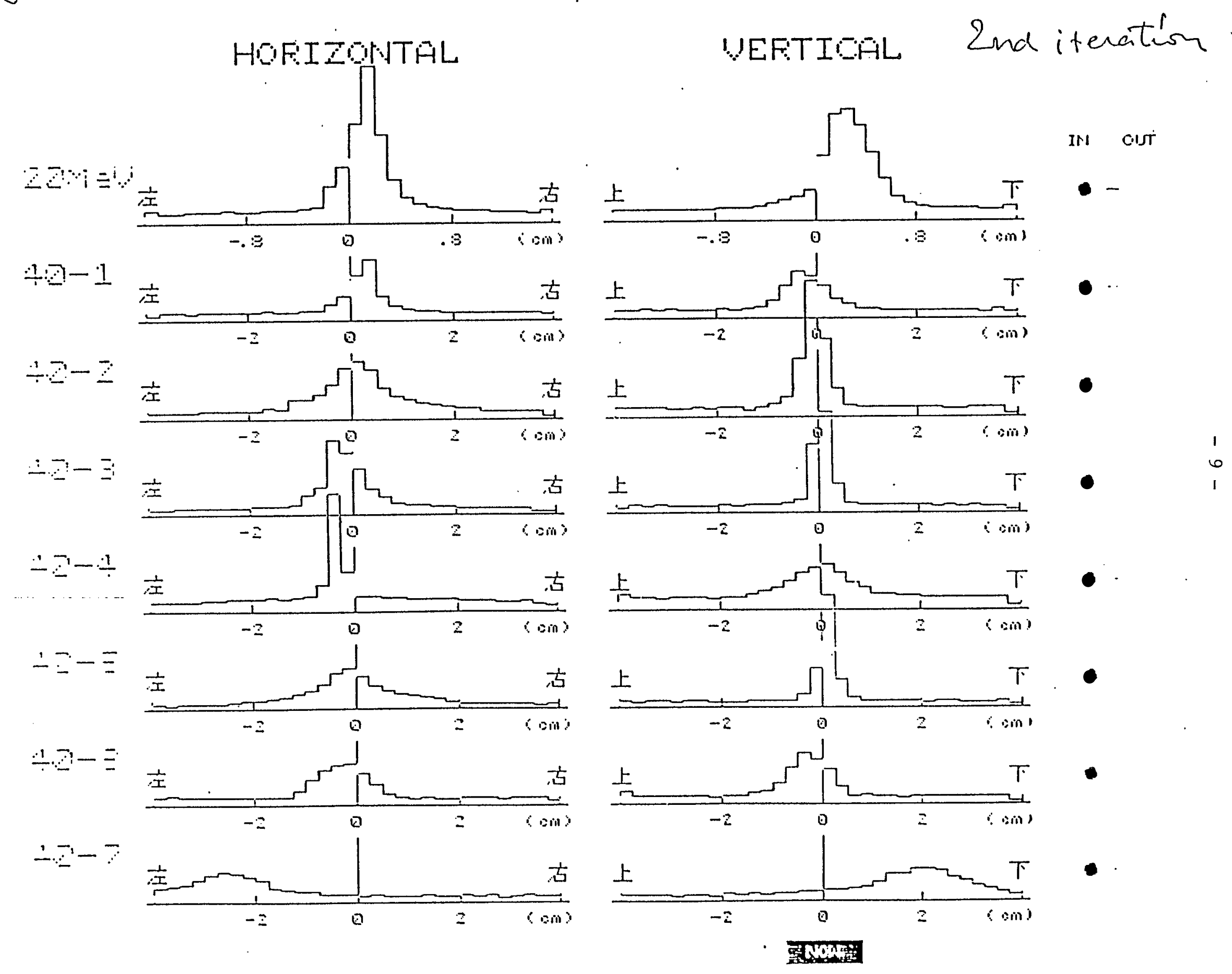



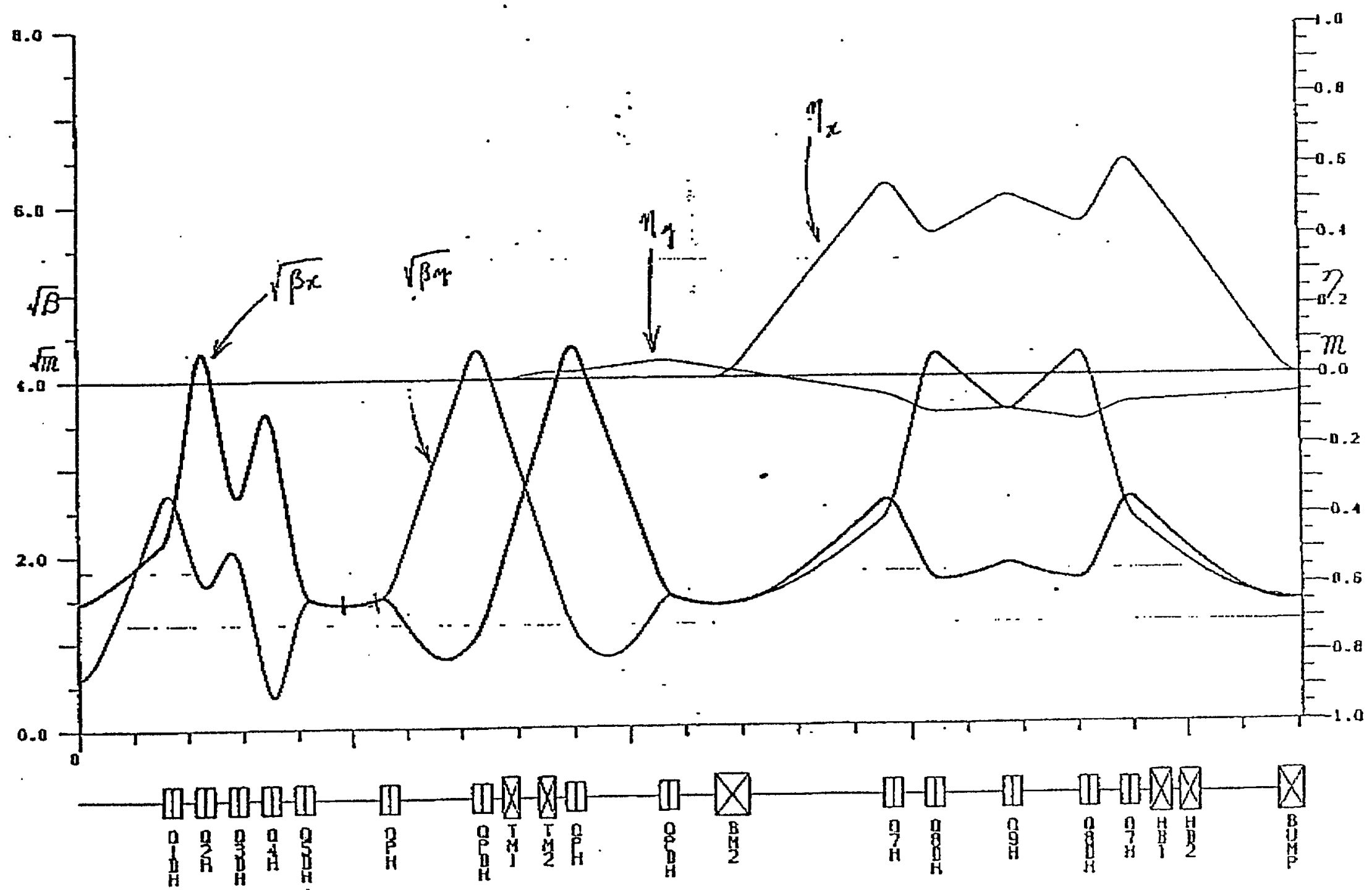

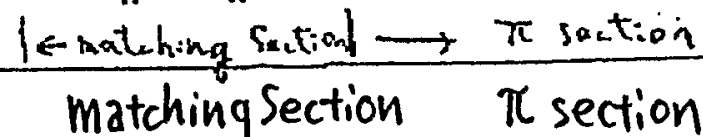

Fig 4 Twiss porameters of the KEK $40 \mathrm{MeV}$ line (trom KEK-PS manual) 


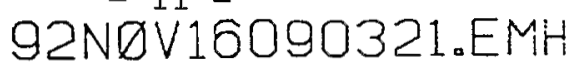
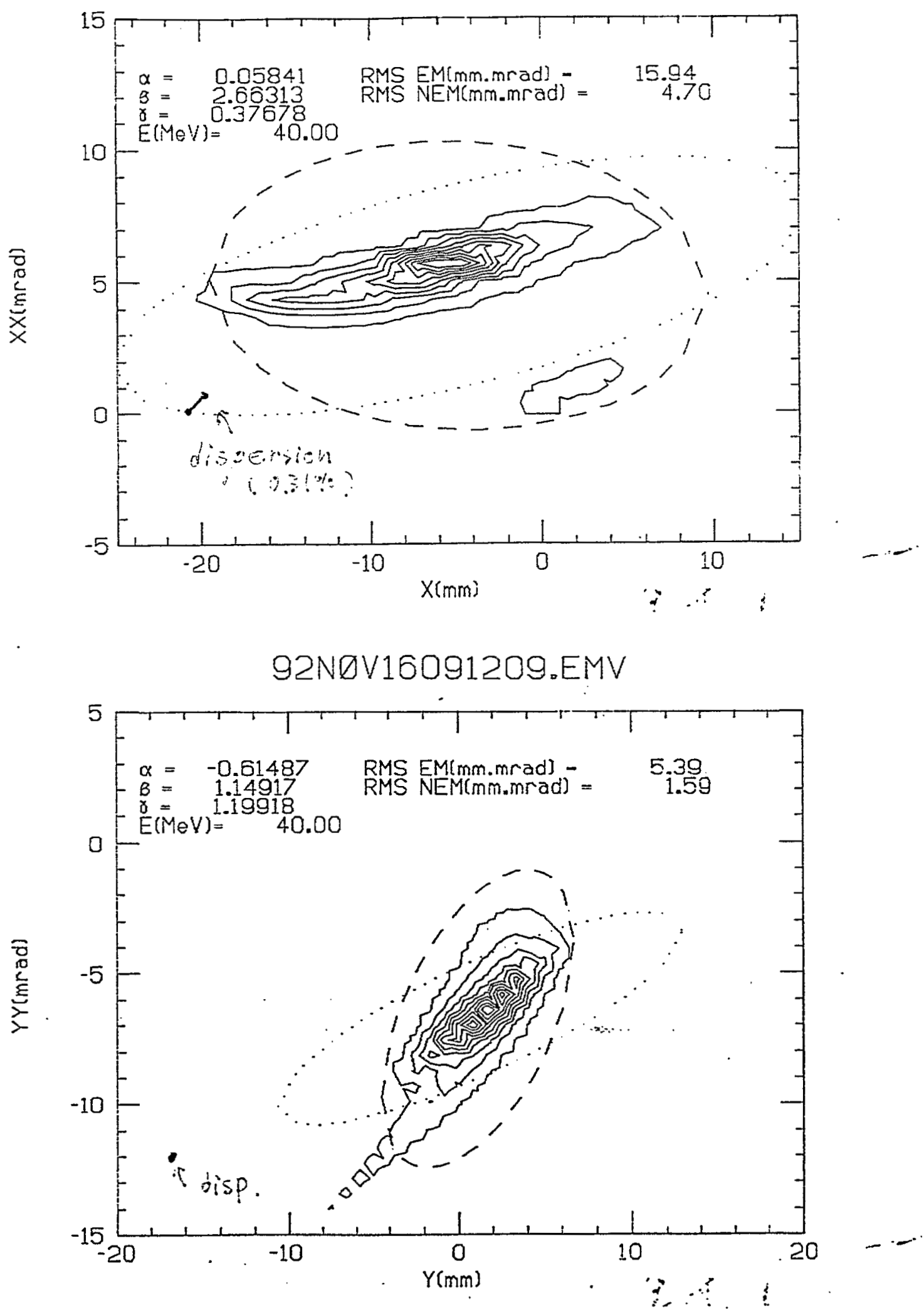

Fig. 5 Example of $40 \mathrm{MeV}$ line emittance

medsured on Nov.16'92.

Broken ellipsoids - RMS emittance

Dotted ellipsoids - Calculated from 7 profiles of MWPM. 


$$
\begin{aligned}
& \longrightarrow \operatorname{beta}(\mathrm{H}) \longrightarrow \operatorname{beta}(\mathrm{V}) \quad 40 \mathrm{MeV} \text { エミッンス } \cdots \odot \cdot \text { alpha }(\mathrm{H})
\end{aligned}
$$

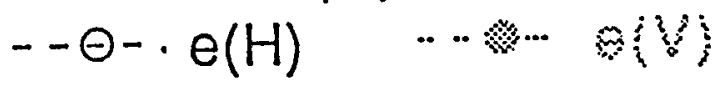

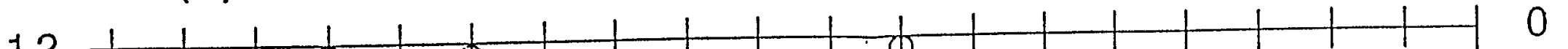

10

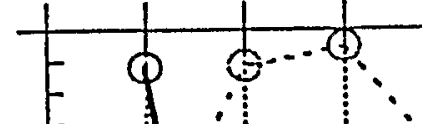

8

6

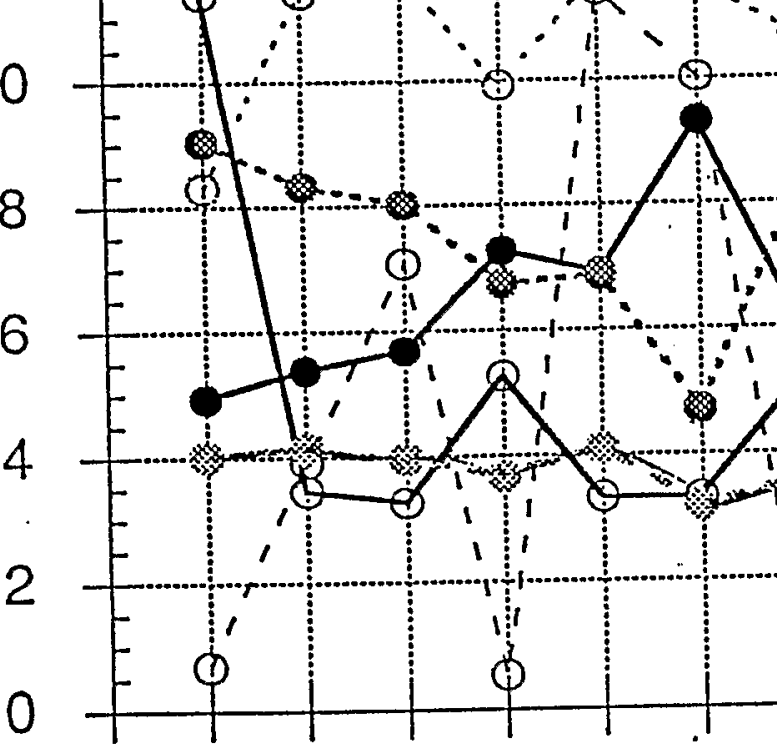

$\varepsilon\left(\pi m m \cdot m r a a_{-}^{\prime}\right.$

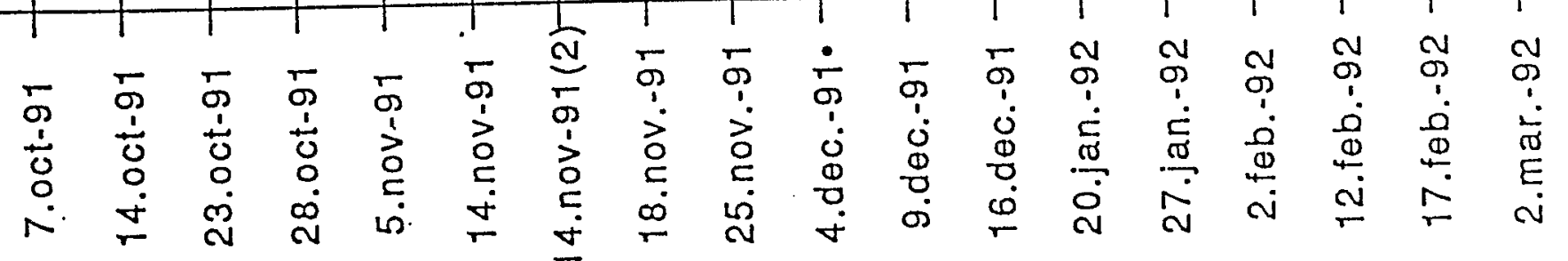

\begin{tabular}{|c|c|c|c|c|c|c|c|c|c|}
\hline & dalo & bota(H) & alpha(H) & $Q(H)$ & bola(V) & alpha(V) & o(V) & $\mathrm{H}$ & 1 \\
\hline$T$ & $7.0 \mathrm{cl}-91$ & 11.390 & -1.8500 & 0.68697 & 4.9300 & -1.4800 & 4.0170 & & \\
\hline$\overline{2}$ & 14.0ct-91 & 3.4500 & -0.29000 & 3.9142 & 5.3800 & -1.8400 & 4.1314 & & \\
\hline 3 & $23.00 t-91$ & 3.2500 & -0.14000 & 7.0668 & 5.6800 & -1.9900 & 3.9634 & & \\
\hline 4 & $28.0 c t-91$ & 5.2600 & -1.0400 & 0.53283 & 7.2500 & -2.6300 & 3.6546 & & \\
\hline 5 & $5 . n o v-91$ & 3.3100 & -0.15000 & 11.432 & 6.9000 & -2.5700 & 4.1005 & & \\
\hline 6 & 14.nov-91 & 3.3000 & -0.22000 & 10.022 & 9.3200 & 3.6400 & 3.1599 & & \\
\hline 7 & 14.nov-91(2) & 5.1400 & -0.66000 & 1.0583 & 6.0700 & -1.9100 & 3.5539 & & \\
\hline 8 & 18.nov, -91 & 4.3100 & -0.84000 & 2.3972 & 3.7600 & -1.0800 & 4.5420 & & \\
\hline 9 & 25.nov.-91 & 3.0200 & -0.37000 & 4.3380 & 1.4700 & -1.3400 & 3.9848 & & \\
\hline 10 & 4.096.-01- & 4.8700 & -0.81000 & 1.6758 & 4.7300 & -1.6800 & 3.7264 & & \\
\hline 11 & 9.dec.-91 & 3.0100 & -0.13000 & 7.3337 & 3.0400 & -0.96000 & 4.4259 & & \\
\hline 12 & 16.doc,-91 & 2.9500 & -0.92000 & 1.2375 & 3.6800 & -1.2200 & 2.7617 & & \\
\hline 13 & 20.jen.-92 & 3.0900 & -0.53000 & 5.7307 & 3.4600 & -0.96000 & 3.8599 & & \\
\hline 74 & 27.jan. -92 & 4.9400 & 0.68000 & 0.85900 & 3.2600 & -1.0400 & 3.6982 & & \\
\hline & & 2.9800 & .0 .40000 & 7.2500 & 3.4300 & .0 .77000 & 1.0500 & & \\
\hline
\end{tabular}

Fig.6-iong term drift of $40 \mathrm{maO}$ line emiftance parameters 
YEASUREYEHT OF HOMENTUH DISTRIBUTION OF THE $40 \mathrm{MEV}$

PROTON BEAH EROM THE KEK ES IIHAC

\author{
HirihikO SOMEYA \\ KEK. National Iaboratory for Hight Energy Fhysies \\ OHo 1-1. Tukuba-shi, Ibaraki 305 JAPAN
}

\title{
AESTRACT
}

Yonentux anaiyzing system for 40 key proton linac was inprovement in order to neasure a time dependenes of the momentum distribution within single beax pulse.By using this system, tuning oprator ean get nore dstaited information on linas bean nomentun.

$$
\text { の枋タ。 }
$$

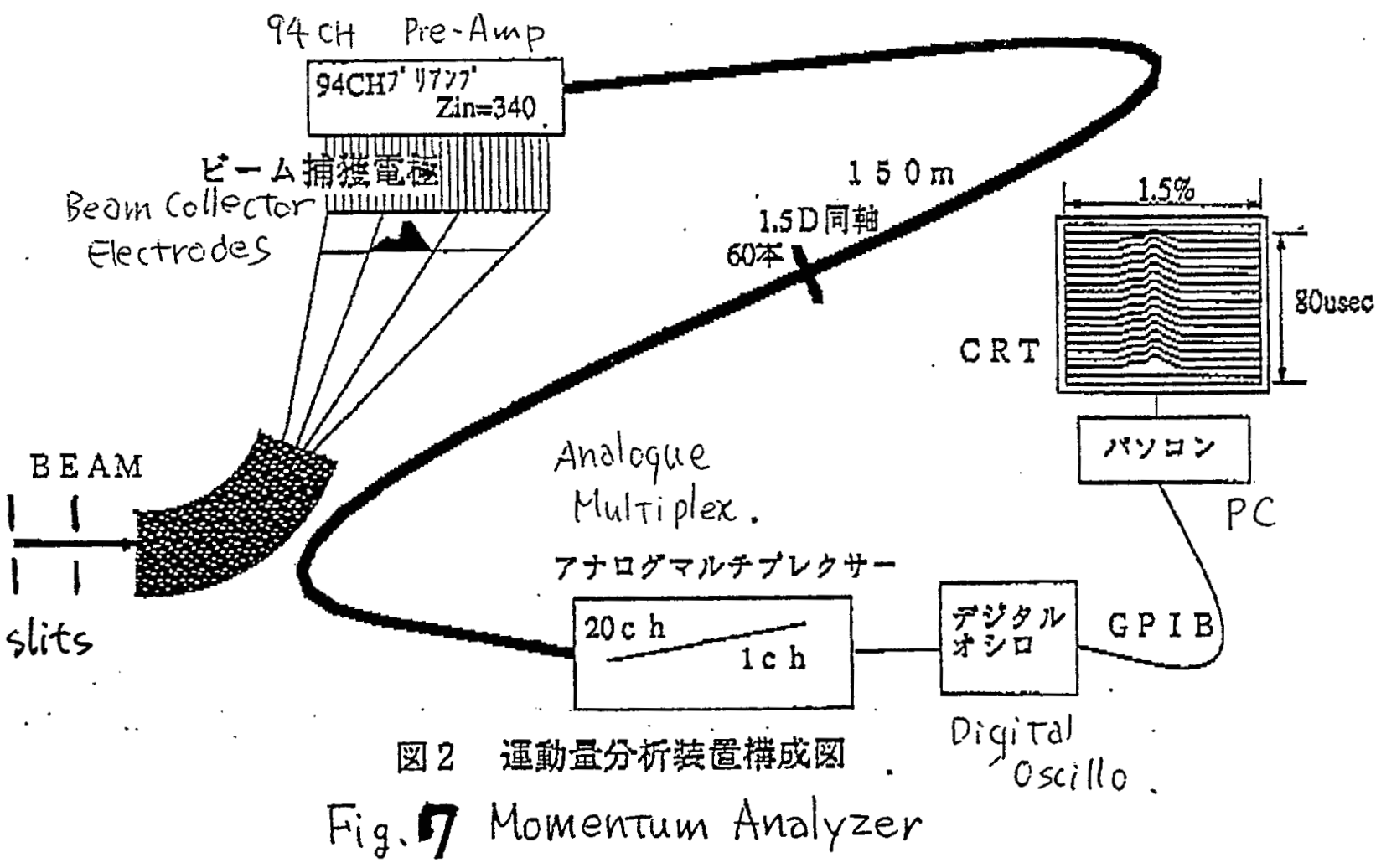


LINAC is

viell tuned

it)
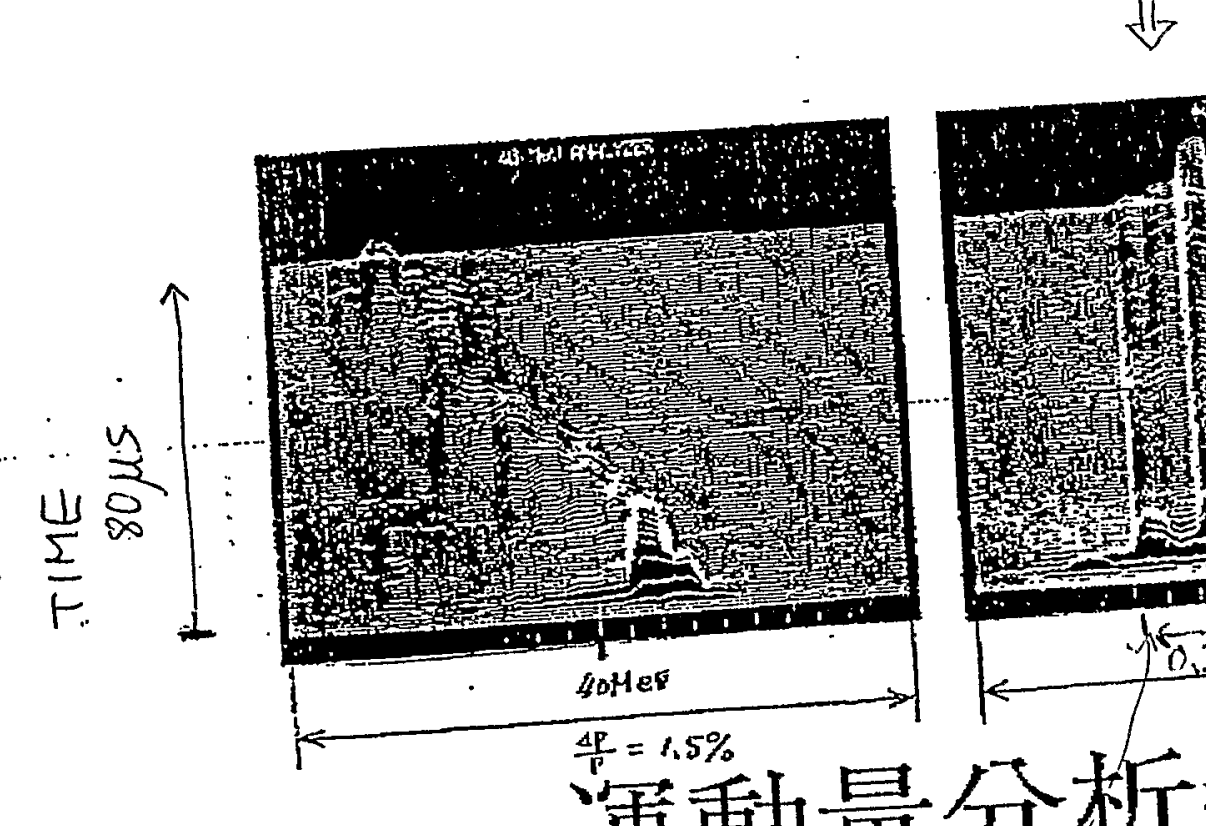

連動量分析装置の出力画像
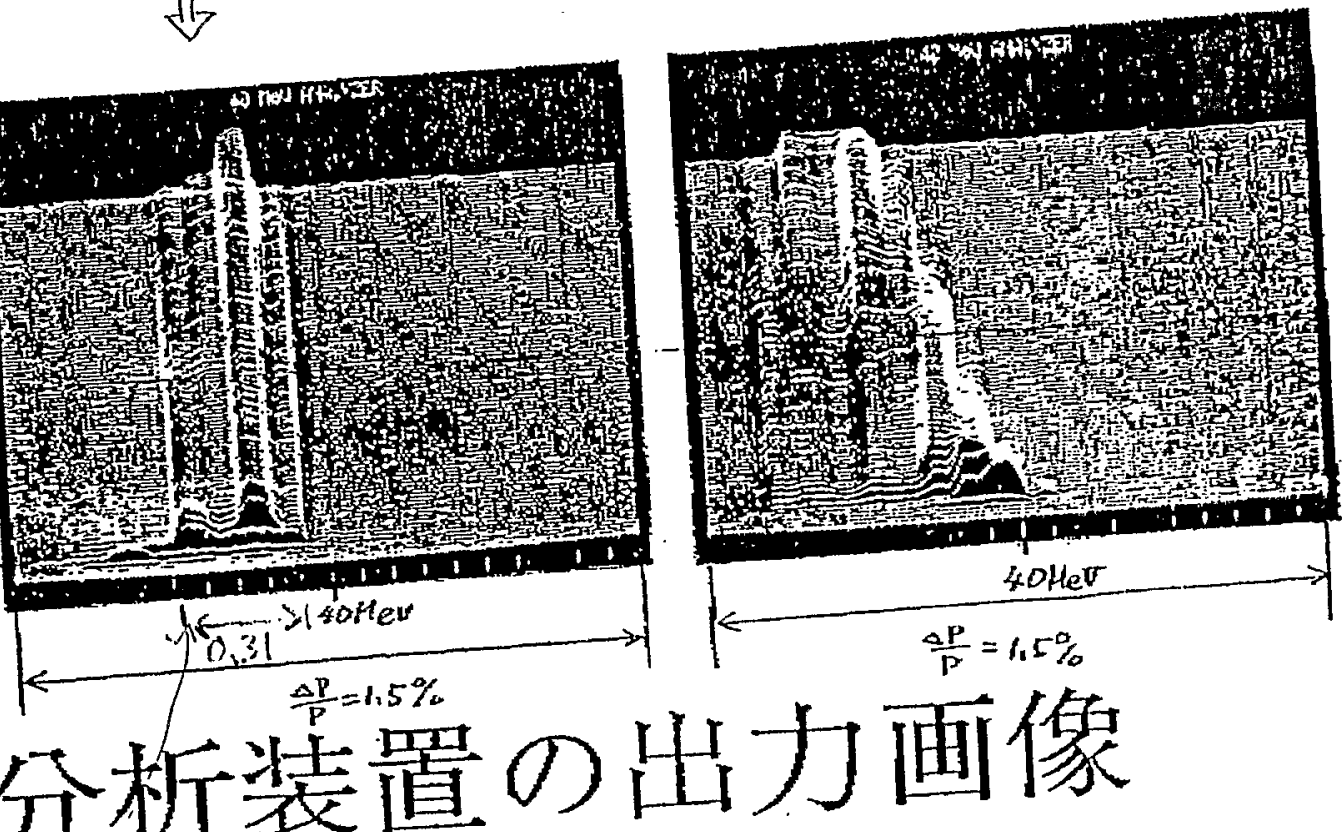

$40 \mathrm{Me}$ proton

Feed bock for the

(onpensa) rion of the

beam loading

was not sufficiently fast.

Fig.8. Typical Displays of the Momentum. Analyzer 
Figure 9 shows $\mathrm{H}^{-}$injection and the injection point. The $\mathrm{H}^{-}$charge exchange injection is like that at the AGS Booster. The bump orbit is produced by four bump magnets and a 30 $\mu \mathrm{g} / \mathrm{cm}^{2} \mathrm{C}$ stripping foil.

$397 \mathrm{eV} /$ pass; 90 turn $=0.045 \% \mathrm{dp} / \mathrm{P}$

Multiple scattering $0.048 \mathrm{mrad} ; 40 \mu \mathrm{s}=0.8 \pi \mu \mathrm{m}(\mathrm{H}), 2 \pi \mu \mathrm{m}(\mathrm{V})$

Charge exchange inefficiency $=2 \%$ (mainly $\mathrm{H}^{0}$ )

Sinusoidal $\mathrm{B} ;(\mathrm{dB} / \mathrm{dt}) / \mathrm{B}_{\mathrm{o}}=0.03 \% / 60 \mu \mathrm{s}$

Number of turns; $60 \mu \mathrm{s}=150$ turns

Figure 10 shows the Booster intensity, rf. This is the typical particle number of the Booster and the rf voltage. It is captured with the adiabatic method. The beam is fully bunched in 200-300 $\mu \mathrm{s}$. This is the beam profile in the Booster measured by NDPM (ionization profile monitor) at KEK developed by Dr. Kawakubo.

Figure 11 shows the Booster NDPM, V. This is the vertical beam size. The left line is the beam for the MR. The right line is the beam for the BSF. The only difference was the time length of the Linac beam. The upper figures show the $90 \%$ beam size during acceleration. The second is the profile just after injection. The third is the profile just before extraction.

Figure 12 shows the Booster NDPM, H. This is the horizontal profile. We saw the obvious intensity dependence of the beam size, especially on the vertical axis. 


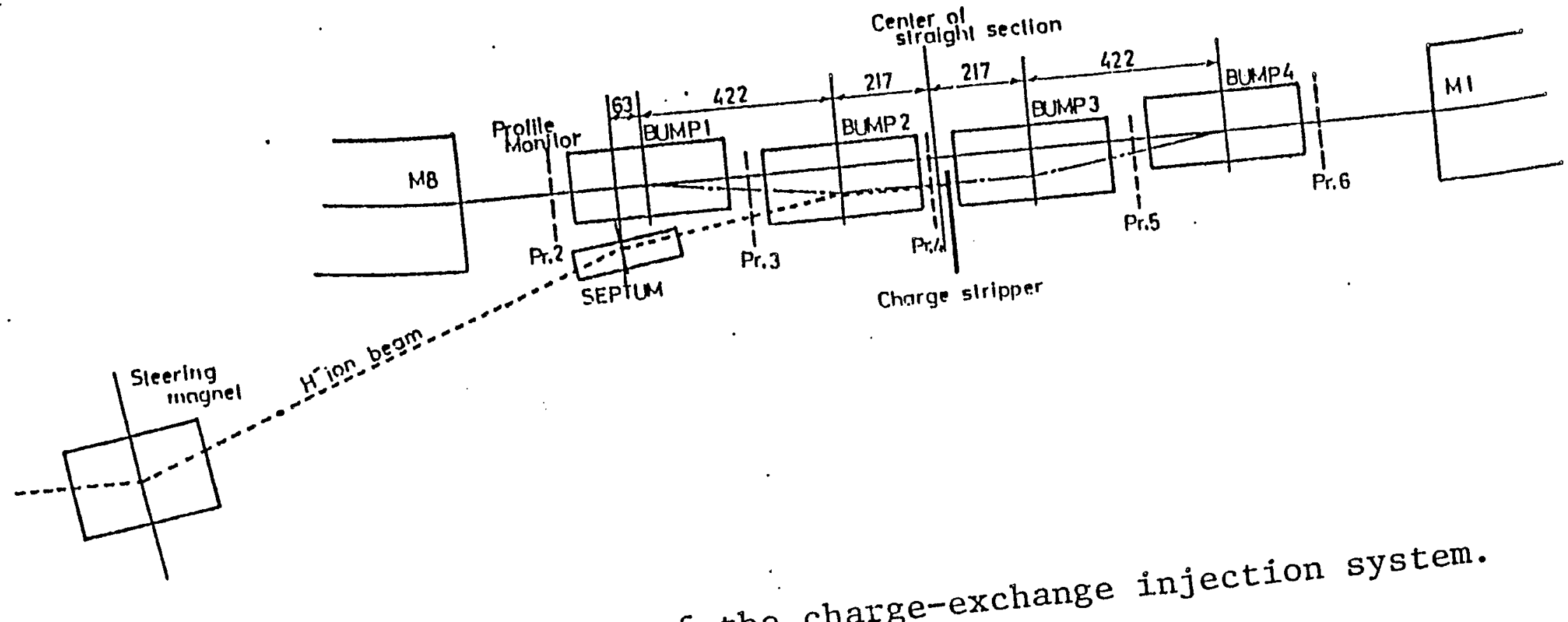

Fig. 9 Layout of the charge-exchange injection syst 274 


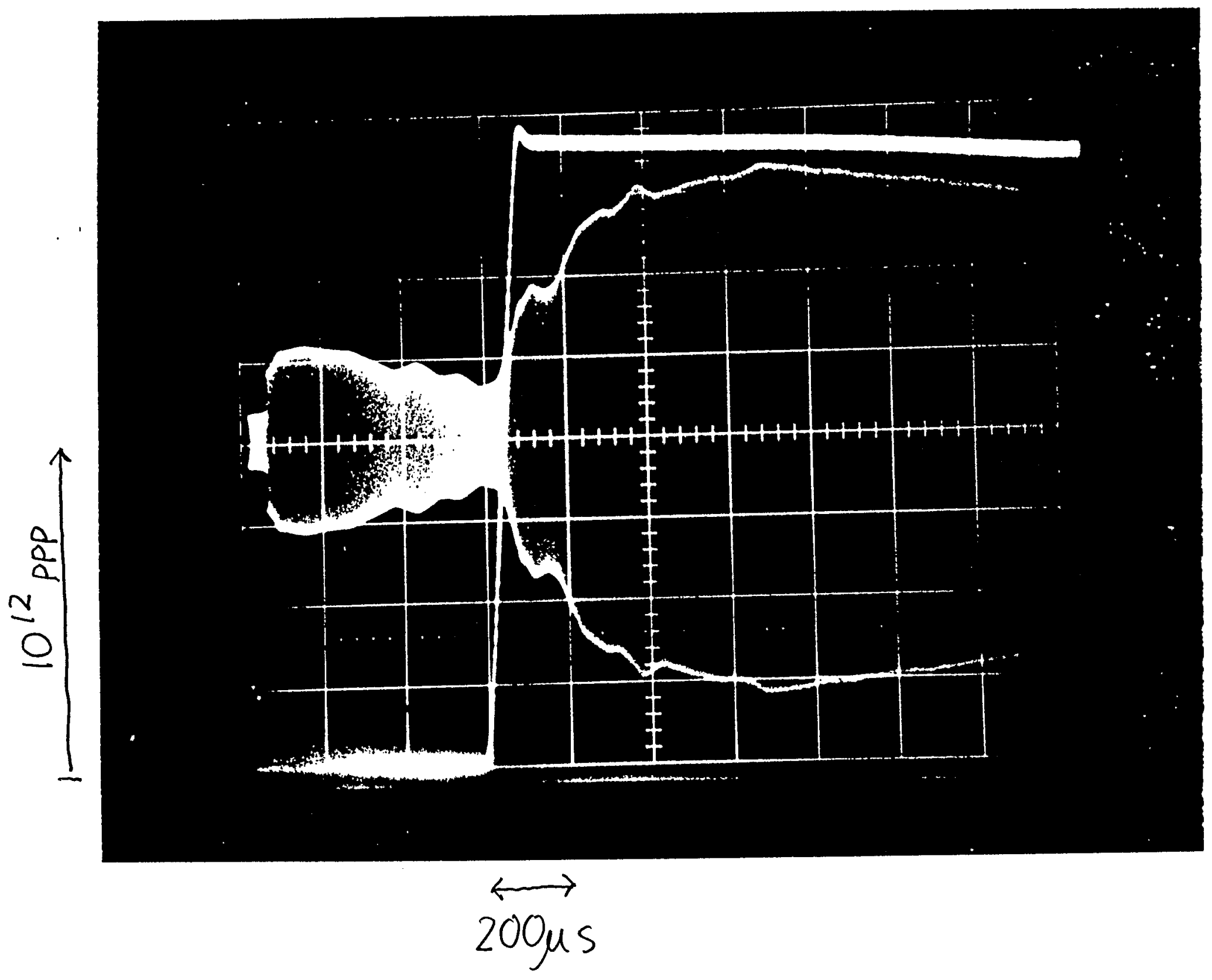

Fig. 10 
Time Dep. of Beam Size

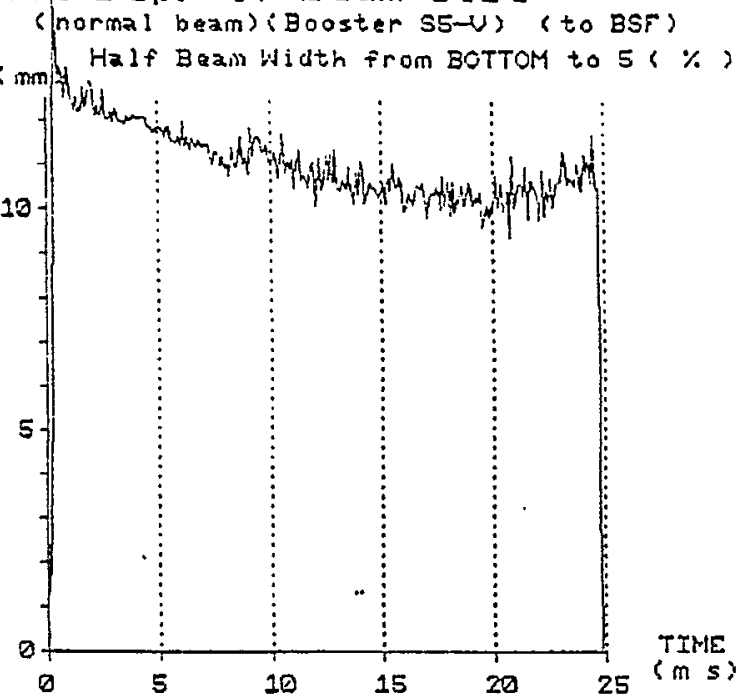

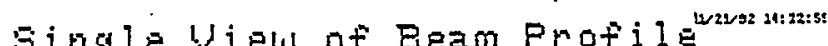
(normal beaii) (Booster Ss-U) (to BSF) at $0.3100(\mathrm{~ms} 8 \mathrm{c})$

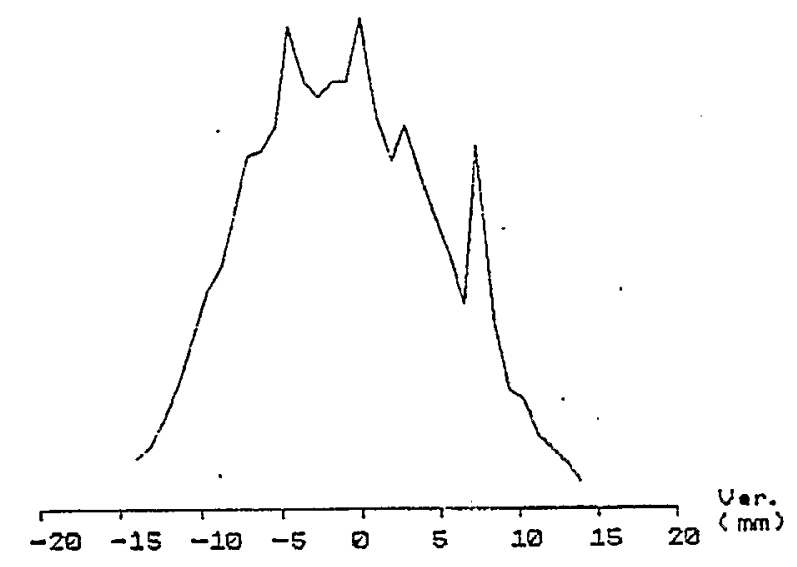

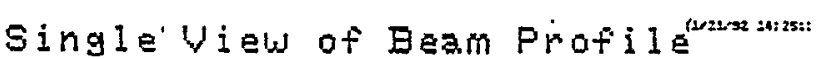
(normal beam) (BDoster S5-U) (to BSF) 2t 23.374 (msec)

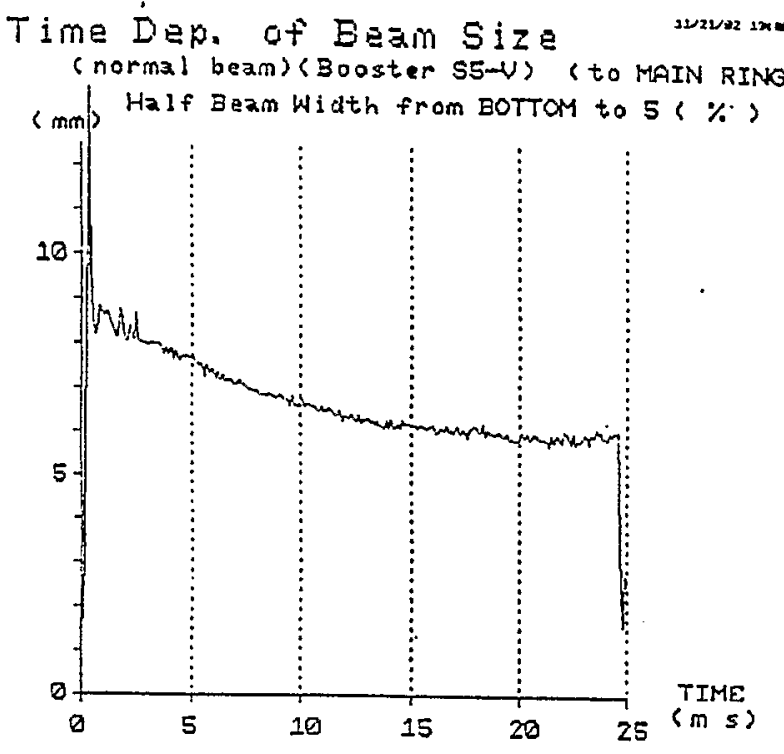

Single Uieul of Beam Profil $e^{1 / 2432 \text { 12:33:23 }}$ (norinal beam) (Bouster S5-U) (to MAIN RING) at 0. 3100 (msea)

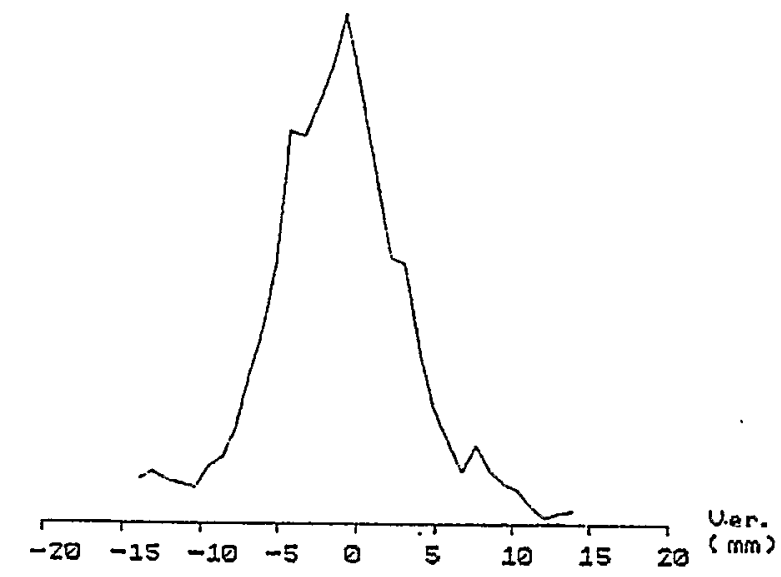

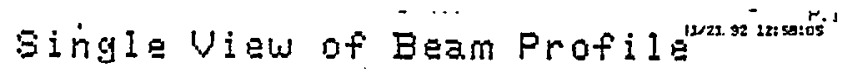
(normal bearn) (Boaster S5-W) (to MAIN RING) at 23.974 (mseo)
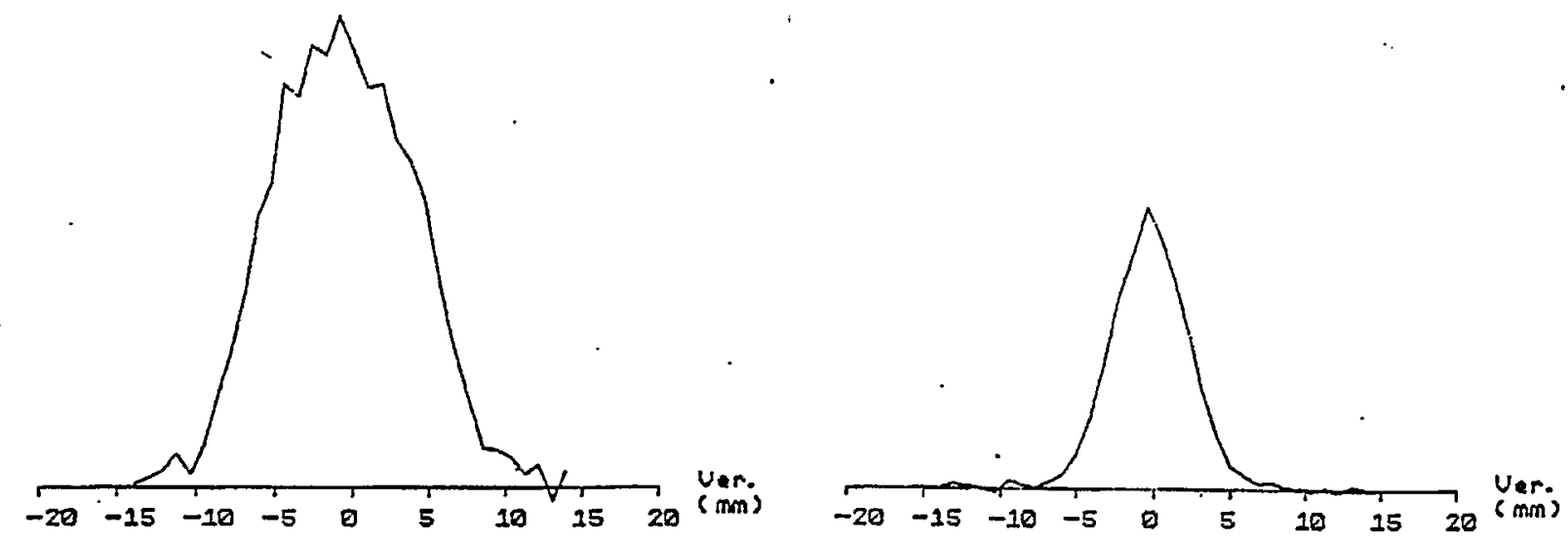

Fig. I1 Vertical BeamProfile in the Booster measured by $\operatorname{NDPM}(=$ IPM)

left: to BSF ( high intensity)

right: to MR (low intensity) 

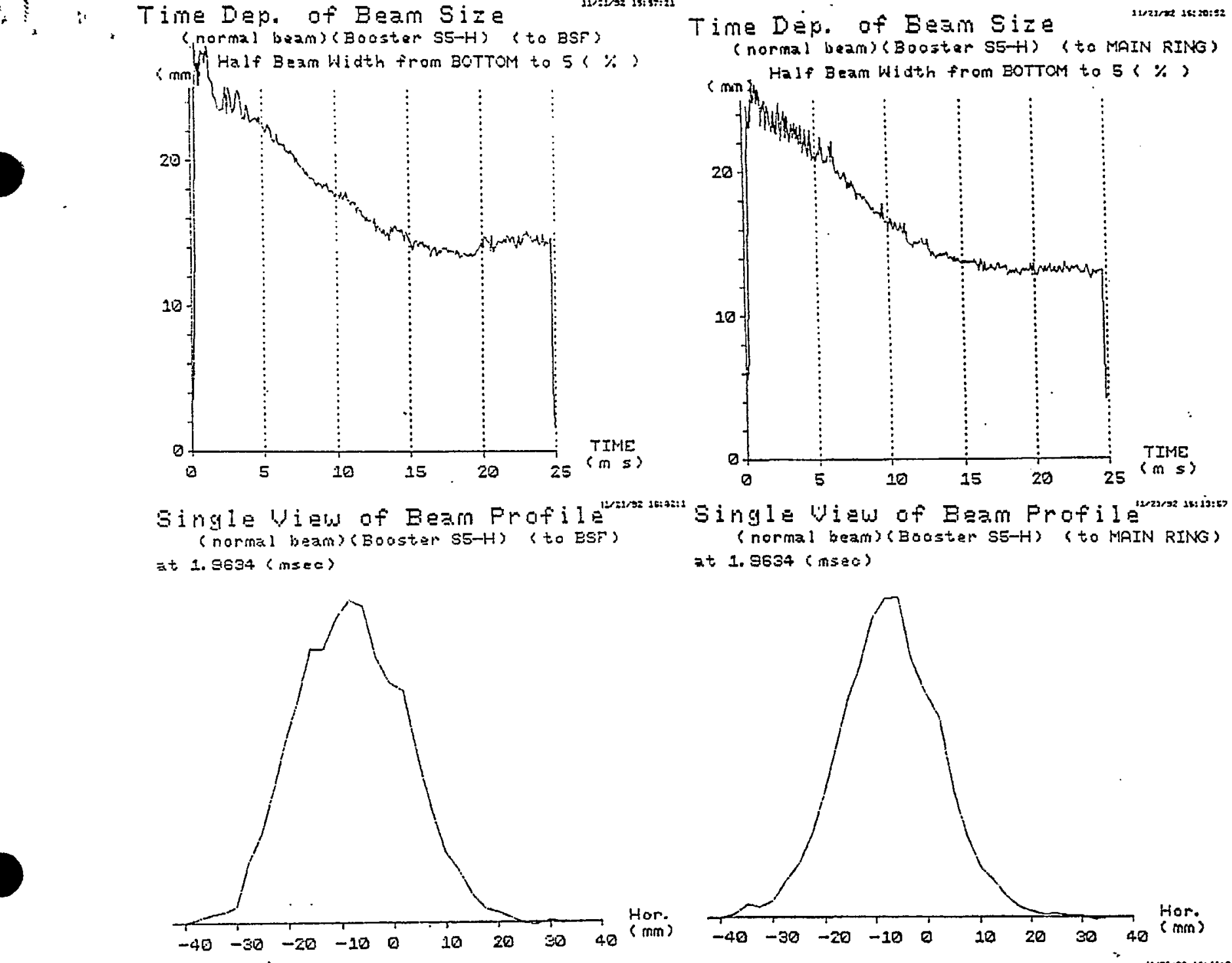

Single View of Beam Profile (normal beam) (Booster. S5-H) (to BSF) at 23.974 (mses) (normal beam) (Booster S5-H) (to MAIN RING)
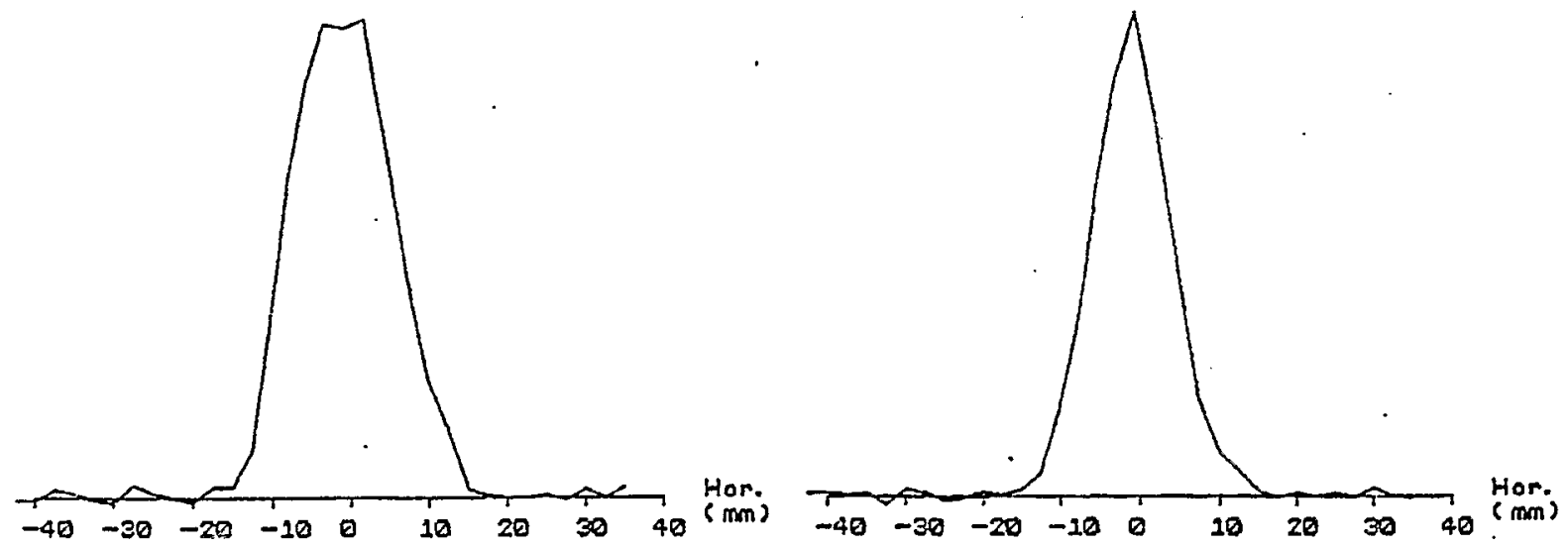

Fig: 12 Horizontal Beam profile in the Booster measured by NDPM ( = IPM ) 


\section{Comparison}

In this section we will compare the KEK-Booster and the AGS Booster.

Table IV shows the Boosters parameters. We do not have time to examine all of these parameters; our interest is in the space charge tune shift.

Table V shows the space charge limits. These emittances are not the phase space area. They must be multiplied by $\pi$ to translate to the area. Values in the brackets are normalized values.

The space charge limits of the KEK-PS and the AGS Booster are calculated in the same way in order to compare them.

$$
\begin{aligned}
& \epsilon_{\max }=\left[\mathrm{X}_{\max _{2}}-\Gamma \beta_{\max }{ }^{*} \mathrm{dP} / \mathrm{P}_{\max }\right]^{2} / \beta_{\max } \quad(\mathrm{H}) \\
& \epsilon_{\max }=\mathrm{Y}_{\max } / \beta_{\max } \quad(\mathrm{V}) \\
& \mathrm{dQ}_{\mathrm{X}}=\left[\mathrm{N} \mathrm{r}_{\mathrm{o}}\right] /\left[\pi \beta^{2} \tau^{3}\right] / \epsilon_{\mathrm{x}}\left[1+\sqrt{\epsilon_{\mathrm{y}} / \epsilon_{\mathrm{x}}}\right][\mathrm{G} / \mathrm{B}][4 / 3] \\
& 1 / \mathrm{B}=3 \quad \text { bunching factor } \\
& \mathrm{G}=2 \quad \text { form factor } \\
& 4 / 3 \quad \text { correction factor of the envelope modification }
\end{aligned}
$$

The space charge limit of the AGS Booster is $3 \times 10^{13} \mathrm{ppp}$ and the limit of the KEK Booster is $2.2 \times 10^{12} \mathrm{ppp}$.

If we want to keep the very low Linac emittance in the ring, we will have big tune shifts and then we cannot avoid the emittance blow up here.

The table shows the calculated tune shifts at the present. These are much higher than expected, but here the form factor is assumed to be 2 . In the real machine it may be smaller because of the painting and the emittances used are $95 \%$ emittance instead of the $100 \%$ emittances; $100 \%$ emittance must be larger. 
Table IV Comparision of the KEK Booster and the AGS Booster

Injector ( LINAC )

pre-injector

kinetic energy

$(\mathrm{MeV})$

curent

normalized emittance $\mathrm{H} / \mathrm{V}$ ( $\mathrm{mm} \operatorname{mrad}$ )

momentum spread

Booster

Circumference

Physical aperture

Betatron tune

Resonance correction

focusing function

$\begin{array}{lccc}\operatorname{maximum} & \text { beta } & \mathrm{H} / \mathrm{V} & (\mathrm{m}) \\ \text { minimum beta } \mathrm{H} / \mathrm{V} & (\mathrm{m}) \\ \text { dispersion } & \mathrm{max} / \mathrm{min} & (\mathrm{m})\end{array}$

Space charge

space charge limit

incoherent tune spread

maximum intensity ( injection, $10^{13} \mathrm{ppp}$ )

$\mathrm{H}^{-}$injection

stripping foil material

stripping foil thickness

beta

alpha

dispersion

dispersion angle

Number of turns

RF capture

harmonic number
( $10^{13} \mathrm{ppp}$ )

3

0.35

3

Carbon

150

$10.93 /$

$-1.505 /$

2.621

0.382

200

Chopped

3
40

10

7.4 / 4.5

0.31 
Table V

INCOHERENT SPACE CHARGE TUNE SHIFTS OE THE BOOSTERS

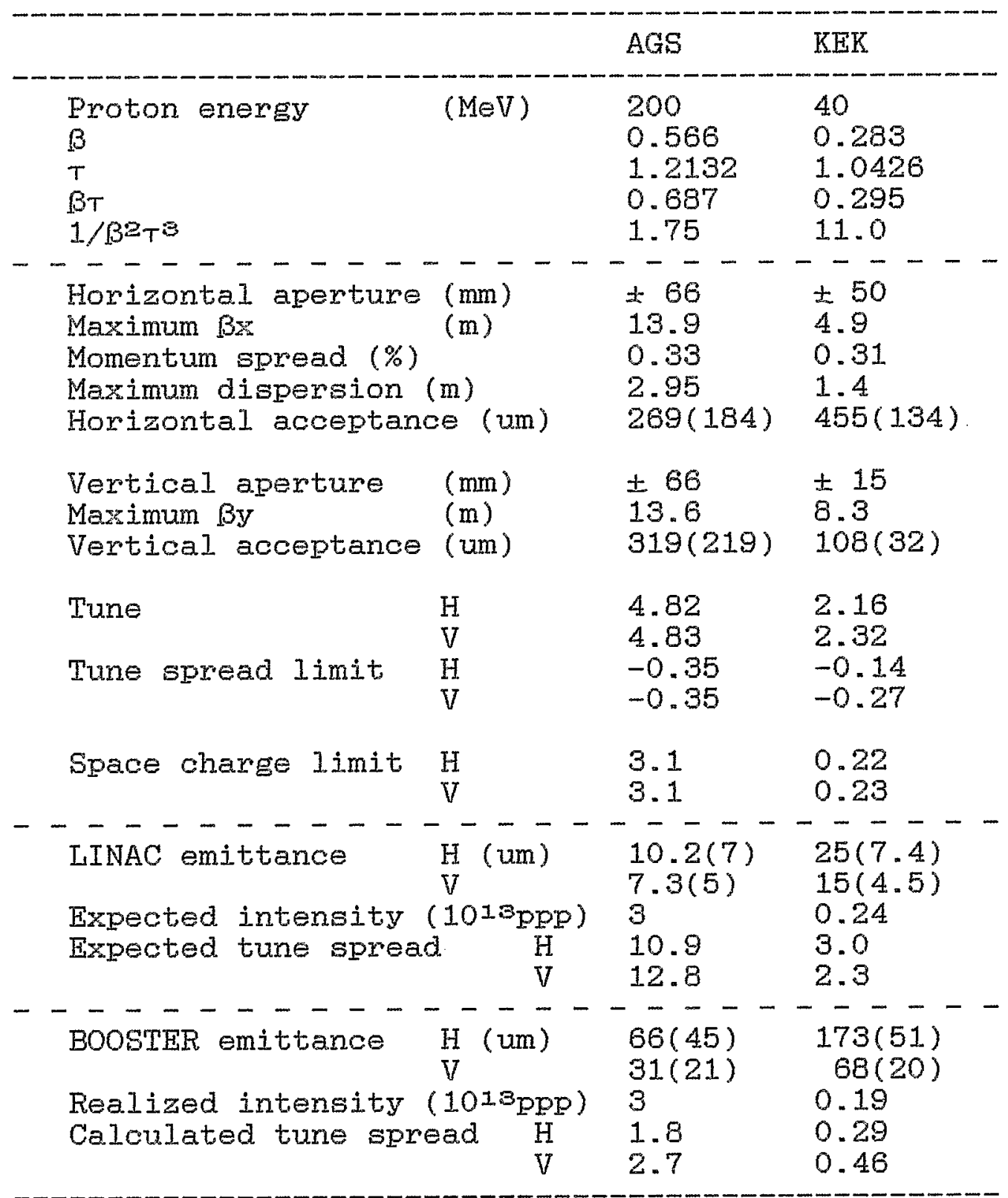




\section{Booster Intensity Improvement}

The intensity of the KEK-Booster was improved from 1987 to 1988 . Then we reached the space charge limit (KEK Ann. Rep. 1988, N. Kumagai, KEK-PS SR-254).

\section{List ii - Intensity Improvement}

$\begin{array}{lll} & \underline{1987} & \underline{1988} \\ \begin{array}{l}\text { Injection Efficiency } \\ \left.\text { (int. } 10^{12} \mathrm{ppp}\right)\end{array} & 90 \% & 97 \% \\ & (1.0) & (2.2) \\ \text { Extracted Int. } 10^{12} \mathrm{ppp} & & \\ \quad \text { Maximum } & 1.5 & 2.2 \\ \quad \text { Routine Operation } & 0.8 & 2.0 \\ \text { Beam Loss at the Booster } & & \text { Slightly } \\ \quad \text { reduced } \\ \quad \text { Pre-Booster } & & 1 / 10 \\ \quad \text { (Linac n level) } & & \end{array}$

Basically, the intensity was improved by delicate tuning. A few new instruments were introduced. The improvement at injection was mainly due to the smaller emittance of the injected beam and the effective acceleration was due to the improvement of the rf. See List iii for parameter tuning that we did at the time. 


\section{LIST iii}

Parameter tuning ( KEK-PS SR-254)

1 LINAC Tank level 1 (2OMeV) and 2 (40MeV)

-- optimum power depends on the intensity

$$
(6.0,5.8) \rightarrow(5.7,6.2)
$$

2 LINAC Tank phase

3 Phases of the pre-buncher and the de-buncher

4. Dipole injection error.

-- easy tuning with $500 \mathrm{MeV}$ line profile

5 Beam injection timing

( relative to Bmin and Bump)

-.- change $\mathrm{Db} / \mathrm{dt}$ ( to lower $\mathrm{dB} / \mathrm{dt}$ )

$\rightarrow$ improve adiabatic capture

$6 \quad 40 \mathrm{MeV}$ line Q-magnet currents

7 LEBT ( WC to LINAC ) Q-magnet currents

--- LINAC transmission was improved

below $0.5 \rightarrow$ over 0.6

8 Vertical steering was newly installed into the Booster

9 Reduce Ion source beam current to $1 / 2$

-- IINAC emittance depends on the intensity

$20 \mathrm{MeV}$ emitt. reduced to $70 \%$ of the former

10 Improve ground connection of the Booster RF ---- stable acceleration 
Let's look at some of the data. Figure 13 shows intensity vs. Tank 2. This is the relation between the intensity and the optimum Linac rf power. It is the purely empirical result. When Tank 2 had higher levels, the average intensity was higher. For each point, other parameters are optimized.

Figure 14 shows dipole injection error vs. beam parameters. When there is vertical dipole injection error, the beam parameters respond like that. The peak height of the extracted beam line is most sensitive to the injection error. This time the intensity was $0.5 \times 10^{12} \mathrm{ppp}$ (it is low because the beam goes to MR). The emittance of the Linac beam increases as the beam current.

Figure 15 shows current vs. $20 \mathrm{MeV}$ emittance. The Booster ring looks transparent. That means the status of the injection reflects on the extracted beam. Although the transverse emittances blow up greatly in the Booster, the efforts to minimize the emittance of the injected beam were still important. I don't know why--is it important for the efficient painting?

When the Pre-Booster parameters were optimized to have maximum intensity, the beam profiles in the $40 \mathrm{MeV}$ line were much different from the prediction ( $\pi$-section was not $\pi$ ). Then we decided to replace emittance monitors from $20 \mathrm{MeV}$ to $40 \mathrm{MeV}$. At this time, I found a space on the line and designed the vacuum chambers (with Mr. Murasugi). 


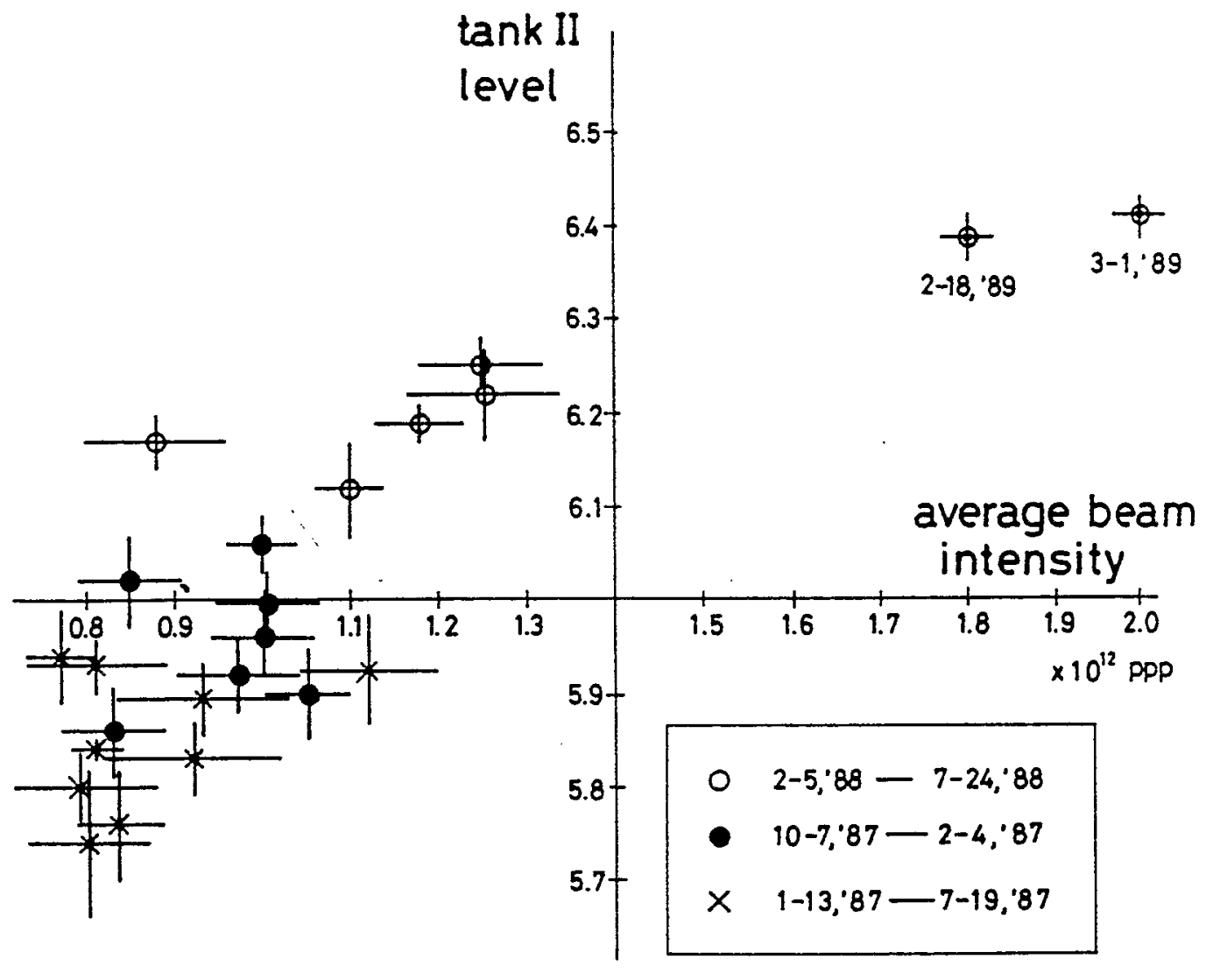

Fig. 13 Correlation between the average beam intensity of the Booster Synchrotron and the if power level of the Proton Linac tank II. 


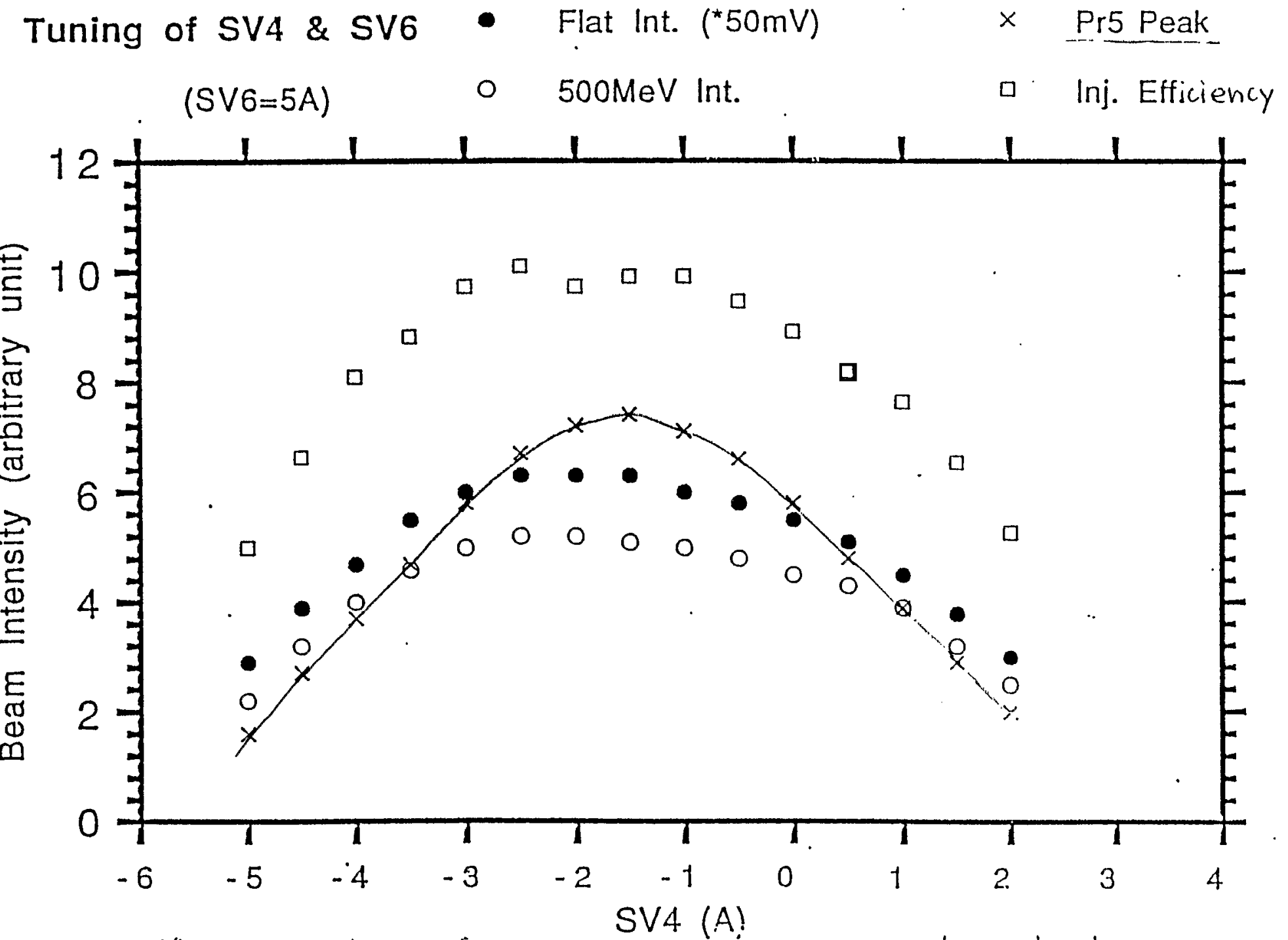

Fig 14 Sensitivity of beom size parameters to the injection error M. Kihara 191 
20 NeV エミッタンス

$-29-$

$20 \mathrm{MeV}$ emittance
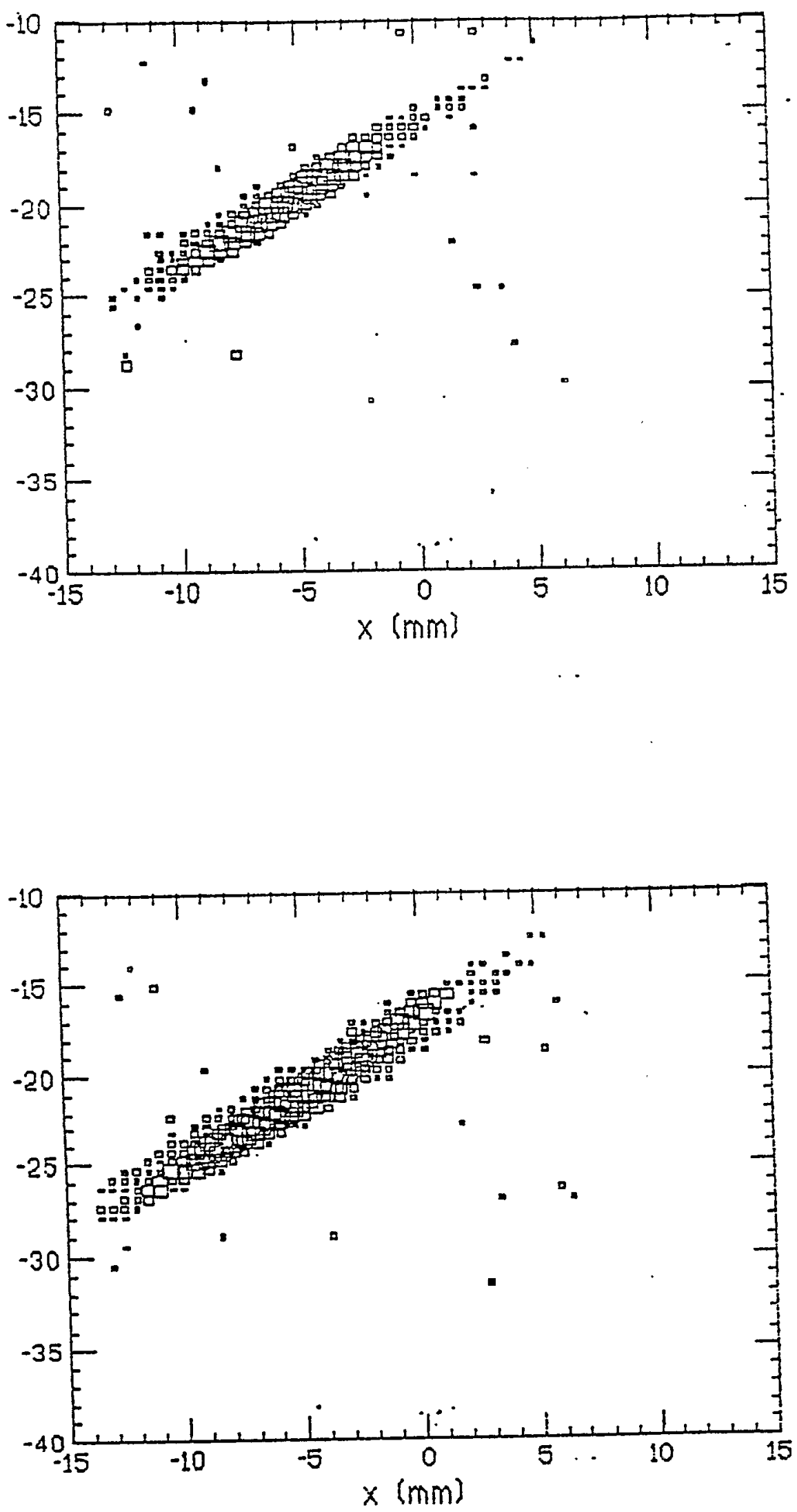

Pre-Injector.

$\eta .5 \mathrm{~mA}\left(w_{0} c_{.}\right)$ 


\section{Intensity vs. Beam Size}

When the accelerators were well tuned, and the intensity was close to its space charge limit, what happened? The most important result was the intensity dependence of the beam size in the Booster.

Figure 16 shows the beam size vs. intensity. As the beam intensity increased, the beam size increased gradually, but the particle density at the center of the beam did not. It had a limit. It looked like there was a hard core in the beam. At low intensity, the beam profile looked Gaussian, but at the high intensity it looked more trapezoid (which had a smaller form factor). The intensity was limited by the aperture of the vacuum chamber, in this case $30 \mathrm{~mm}$. It is reasonable! It was measured with the combination of the beam scraper and the fast study bump. The vertical bump rises to the top in $200 \mu \mathrm{s}$.

Figure 17 shows the S3 scraper and the fast study bump.

\section{List iv - Beam Size Measurements}

We changed the speed of the fast bump, but the result did not change.

We changed the intensity through two methods:

1. insert the thinning-out mesh plate into the $40 \mathrm{MeV}$ line.

2. change Linac beam pulse width

There was not meaningful difference between these.

The beam profile of the extracted beam showed similar results.

With the accelerator finely tuned, then there were no serious beam losses in the Booster.

I am not sure whether we performed the painting, perhaps so. The parameters are tuned to obtain the maximum intensity with the minimum beam size. It was possible that we painted the beam, but not on purpose! 
$-31-$
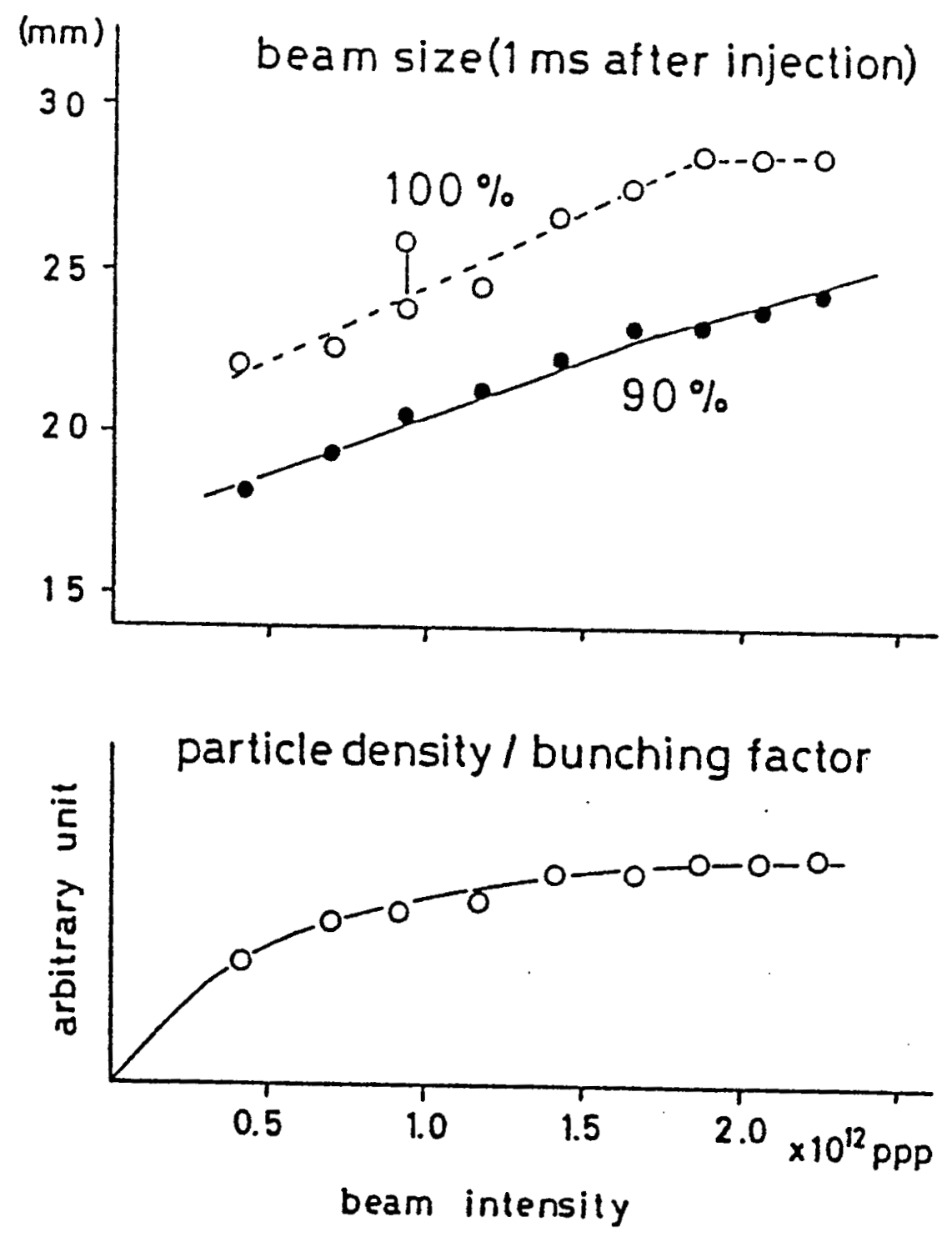

Intensity dependence of the vertical beam size 1 msec after injection.

: Fight

KEK Ann. Rep. 1988 よ" 
$-32-$

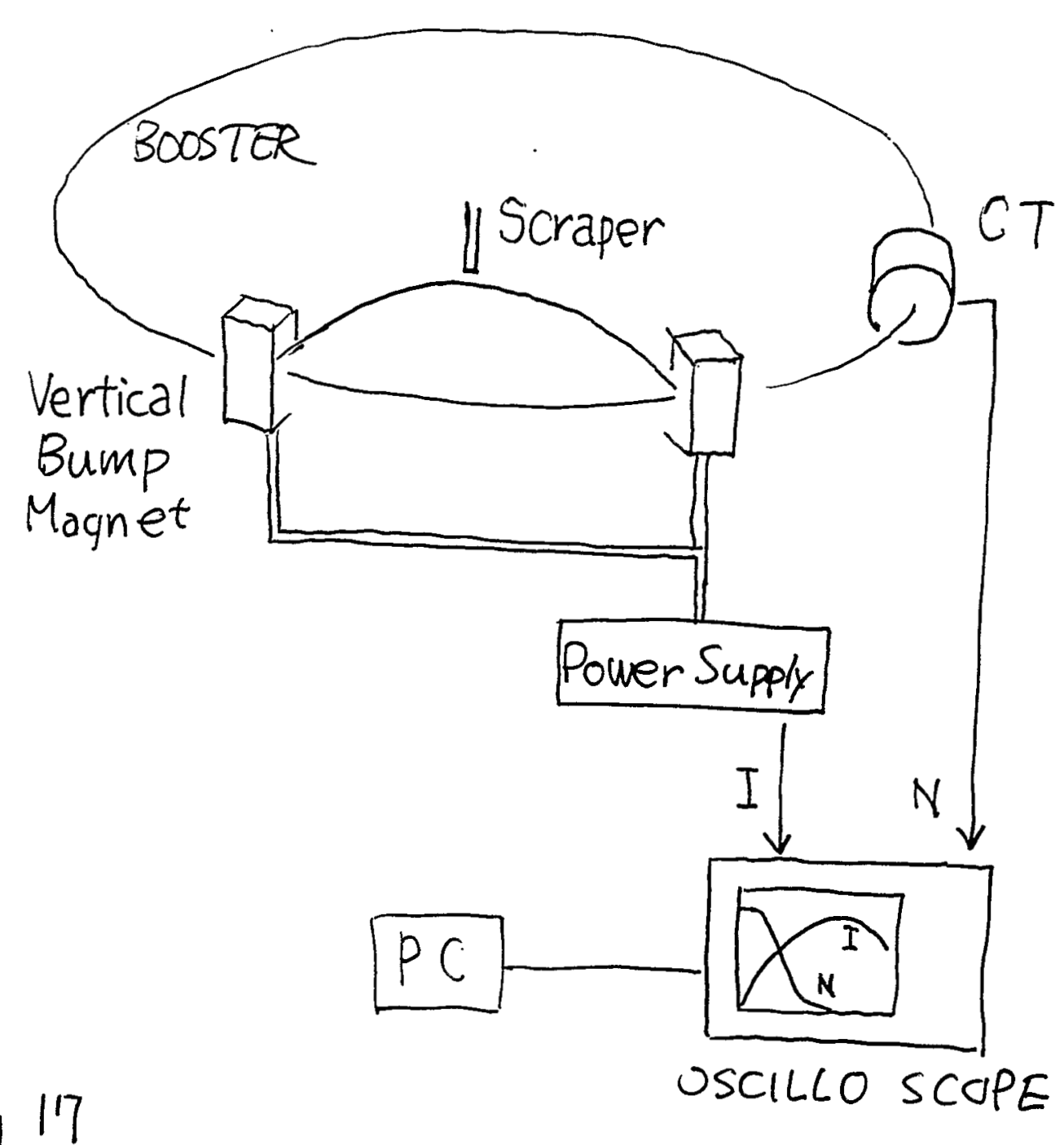

Fig 17

We changed the speed of the fast bump

But the result did not change

We changed the intensity through two methods

1. insert the thinning-out mesh plate into the $40 \mathrm{MeV}$ line

2. change linac beam pulse width

No meaningful difference between these

The beam profile of the extracted beam shows the similar results

The accelerator was best tuned

Then there were no serious beam loss in the Booster 


\section{Transverse Twiss Parameter Matching}

At the KEK-PS the emittance of the Linac beam is basically thought to be not predictable. Figure 18 shows the Linac emittance fluctuation. Shown are the emittances at the exit of the Linac. It is different for each three-week cycle; sometimes it is different every week. It would not be impossible to stabilize this emittance, but the adjustment of the transport line is much easier.

\section{List v -- Matching Procedure}

1. Measure the emittance by the Emittance Monitor (2d density distribution).

2. Calculate the beam image at the stripping foil $(\alpha=$ $0)$.

3. Calculate the Twiss parameter (eye-ball fit).

4. Calculate the Twiss parameter at the exit of the Linac.

5. Calculate the $40 \mathrm{MeV}$ line Q-magnet currents (use MAGIC).

6. Change Q-magnet current.

7. Measure again. 
$-34-$
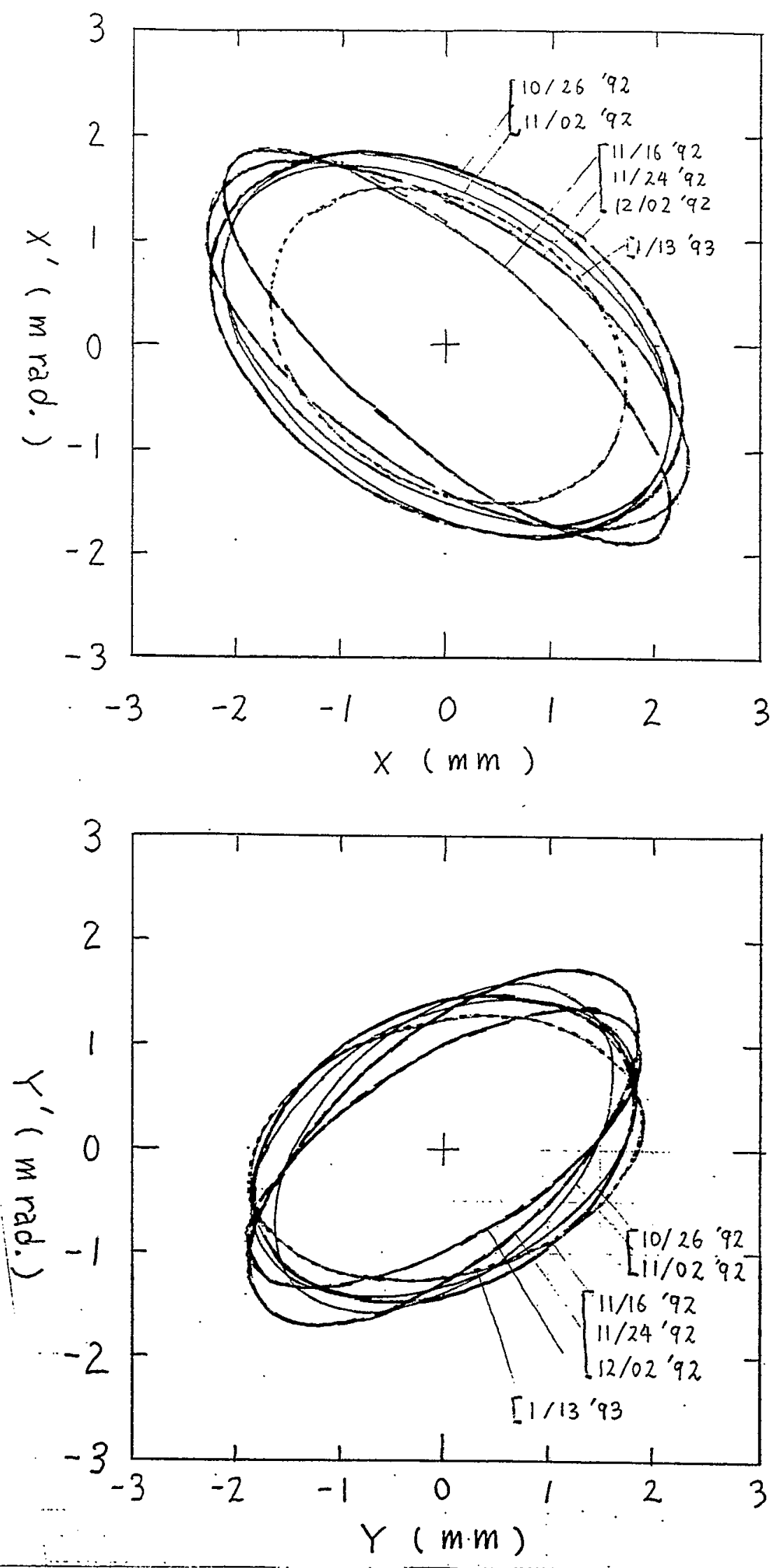

Fig. 18

Transverse emittance at the exit. of the LINAC meas. by Adachi, plotted by Shoji 


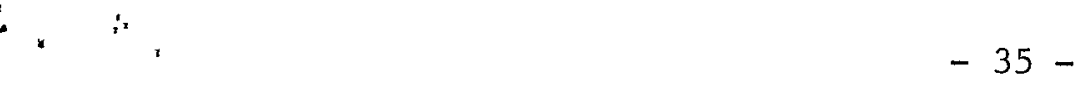

Figure 19 shows the matching procedure. The top figures are the particle distributions in the phase space at the EM slit. The middle figures are the beam image at the stripping foil. Here $\alpha=0$, then it can be easily recognized. The third figures are the same image after the matching procedure. They are close to the calculated matching conditions. We needed no iteration, that means the Q-magnet adjustment takes place only once. The transport line is well understood and is reliable. That procedure works but it has some problems.

\section{List vi -- Problems of the Procedure}

1. We did not subtract the contribution of the dispersion.

2. It is difficult to make simultaneous matching of the Twiss parameters and the dispersion (misdesigned ?). We have to separate the power supplies in the achromatic section (Q10 - Q14).

3. It takes a long time (5 min.). We had to stop the beam during the measurement.

4. The particle density distributions are not the simple ellipsoid. Eye-ball fit depends on personality. Difference (center and edge).

5. Only a small improvement was obtained. 


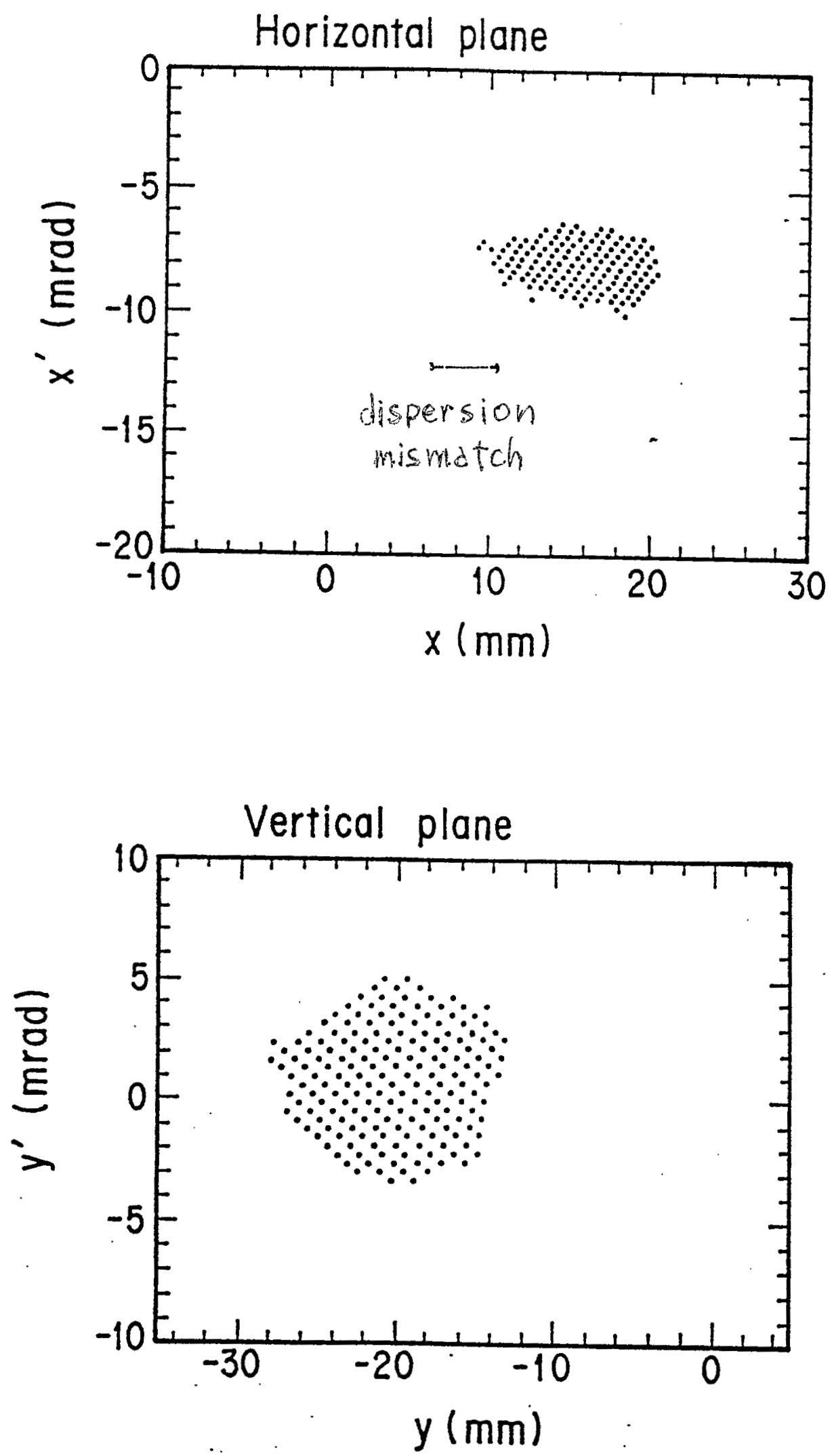

Fig. 20 Transverse phase-space distribution at the injection point. This phase-space distribution was calculated using the observed emittance and new currents of the 


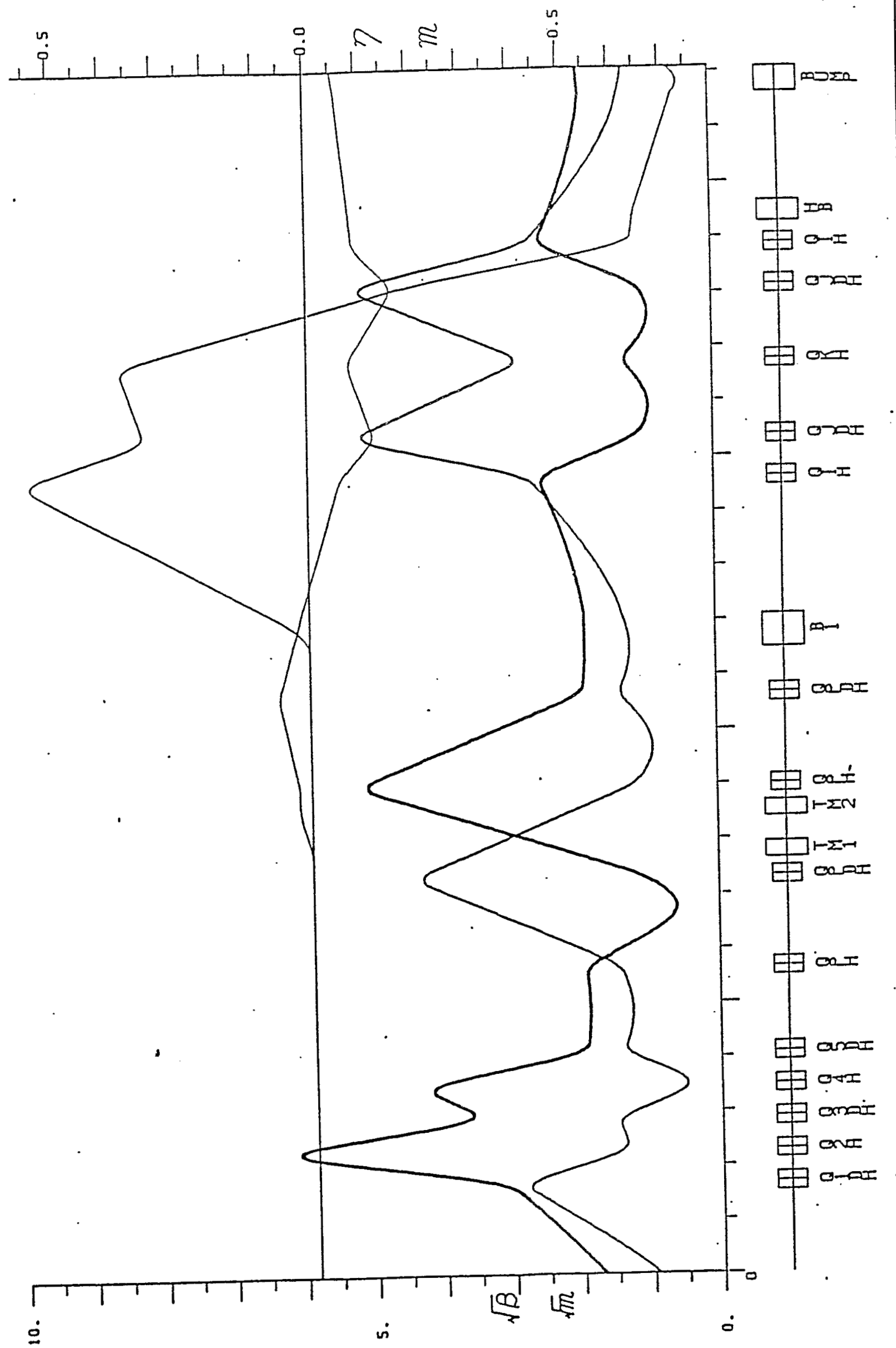


92NDV16090321.EMH

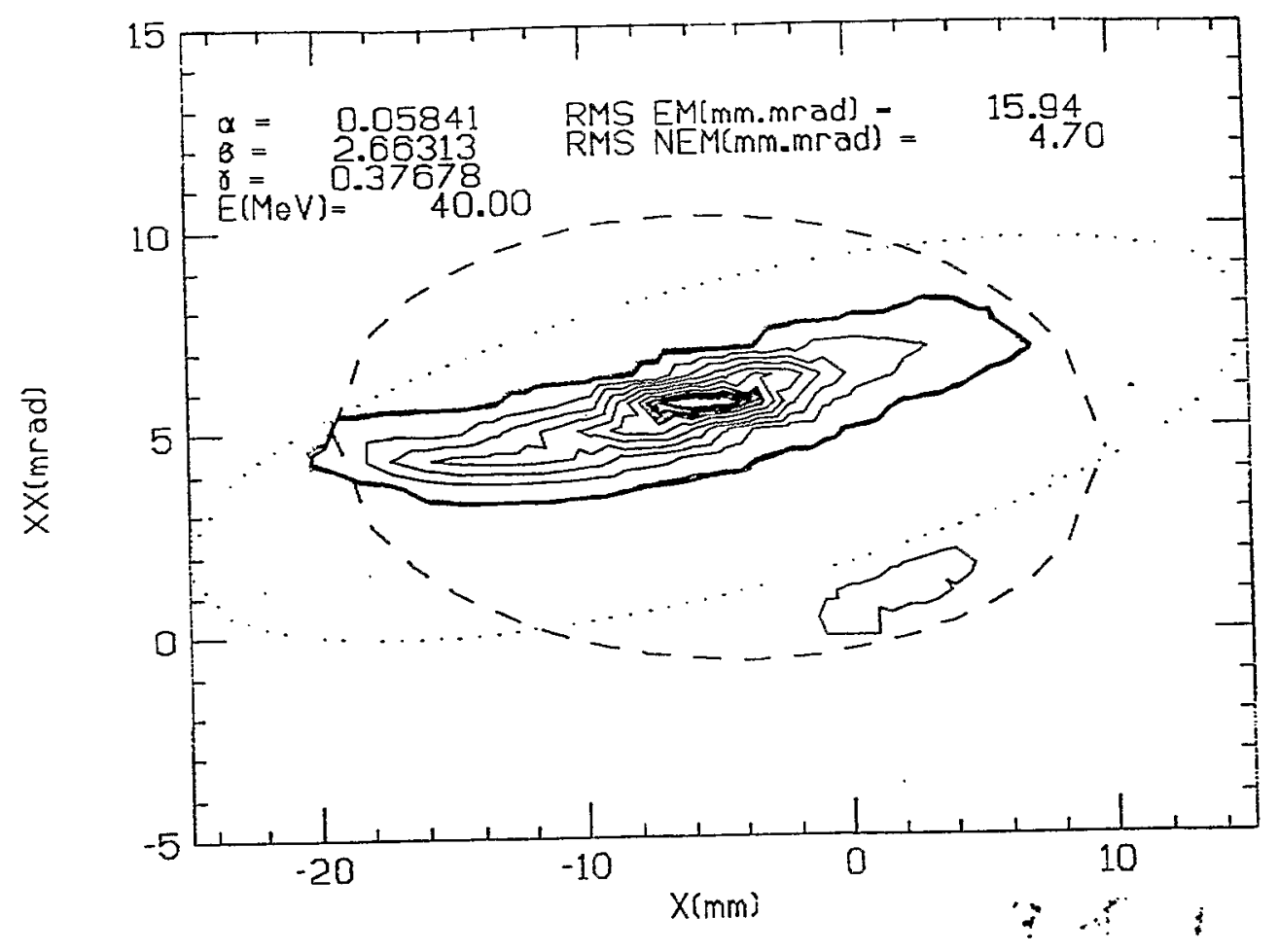

92NDV16091209.EMV

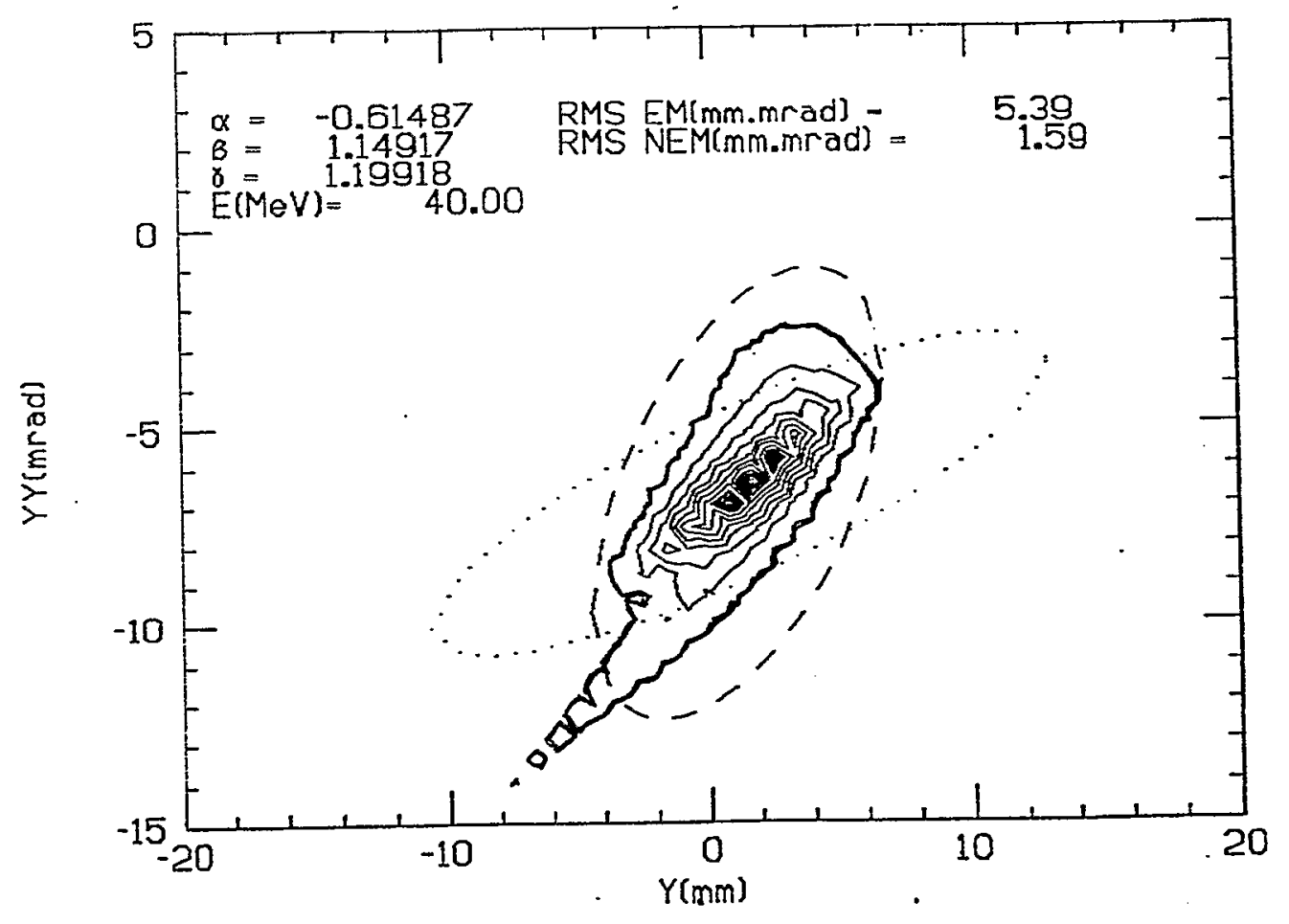

Fig. 21 Example of $40 \mathrm{MeV}$ line emittance medsured on Nov.16' 92 .

Broken ellipsoids - RMS emittance

Dotted ellipsoids - Calculated from 7 profiles of MWPM. 
$-41-$
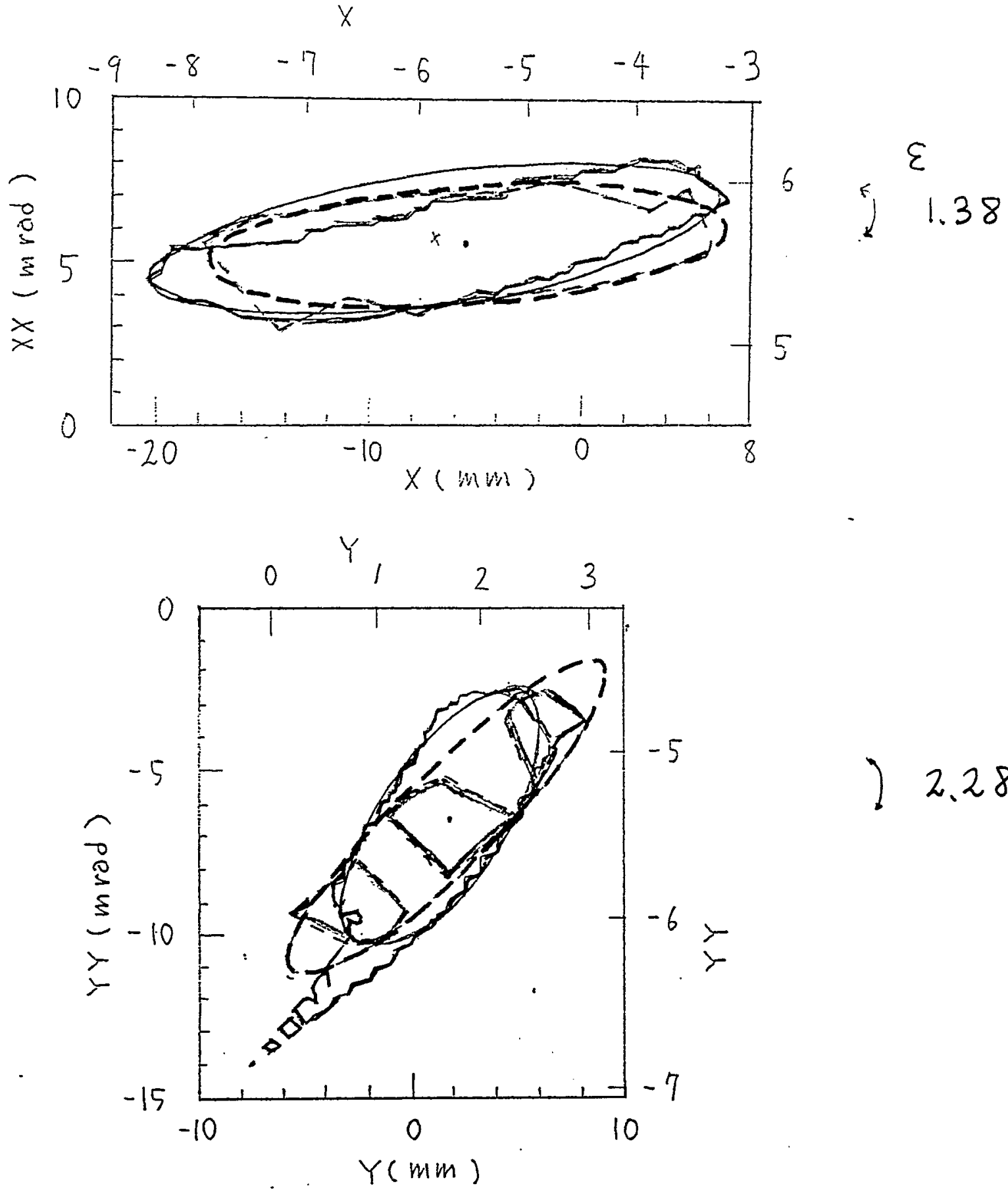

Fig. 22 Approximated ellipsoids

matching -center

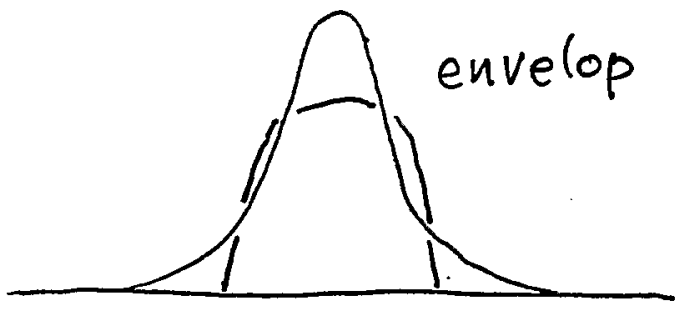





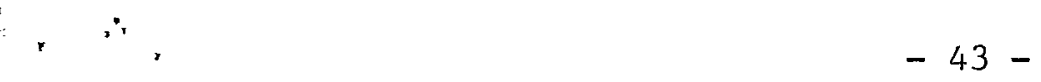

The main control computer (VME) controls the whole process: profile measurement, parameter fitting, lattice calculation, and Q-magnet power supply control. Automatic control is planned for the future. The VAX is not connected to the VME.

Table VI shows the emittances by the various methods. They are different from each other. The RMS emittances are not correct because the far-aside islands are taken into consideration. The discrepancy is about a factor of 2 (emittance blow-up factor).

Figure 23 shows the 14 profile fit. The Gauss fittings are not always good in some channels. The two-dimensional density distribution can produce the profiles (experimentally almost the same), but the fitted profiles cannot reproduce the density distribution.

Figure 24 shows the profiles calculated from the emittance. 
able VI Twiss parameters at the slit of the emittance monitor on Nov.4 ' 92. RMS fit gives the much different value. Because it takes into account the beam halo.

\begin{tabular}{|c|c|c|c|c|c|}
\hline \multirow{2}{*}{\multicolumn{2}{|c|}{ data fitting method }} & \multicolumn{2}{|c|}{ Horizontal } & \multicolumn{2}{|c|}{ Vertical } \\
\hline & & alfa & beta & alfa & beta \\
\hline 1 & RMS fit & 0.66 & 2.66 & -0.61 & 1.15 \\
\hline 2 & Eye ball fit to the envelope & -0.55 & 6.68 & -0.93 & 1.64 \\
\hline 3 & Eye ball fit to the center & -0.47 & 6.84 & -2.18 & 3.73 \\
\hline 4 & Fit $7 \mathrm{MWPM}$ on $40 \mathrm{MeV}$ line & -1.5 & 13.10 & -1.09 & 1.53 \\
\hline
\end{tabular}

data 2 and data 3 data 2 and data 4 data 3 and data 4 emittance blow up factor

$\begin{array}{ll}1.38 & 2.28 \\ 2.09 & 1.08 \\ 2.16 & 2.55\end{array}$

$$
\left(\varepsilon / \varepsilon_{0}\right)^{2}+\left[\left(\beta_{1}-\beta_{2}\right)\left(\gamma_{1}-\gamma_{2}\right)-\left(\alpha_{1}-\alpha_{2}\right)^{2}-2\right]\left(\varepsilon / \varepsilon_{0}\right)+1=0
$$




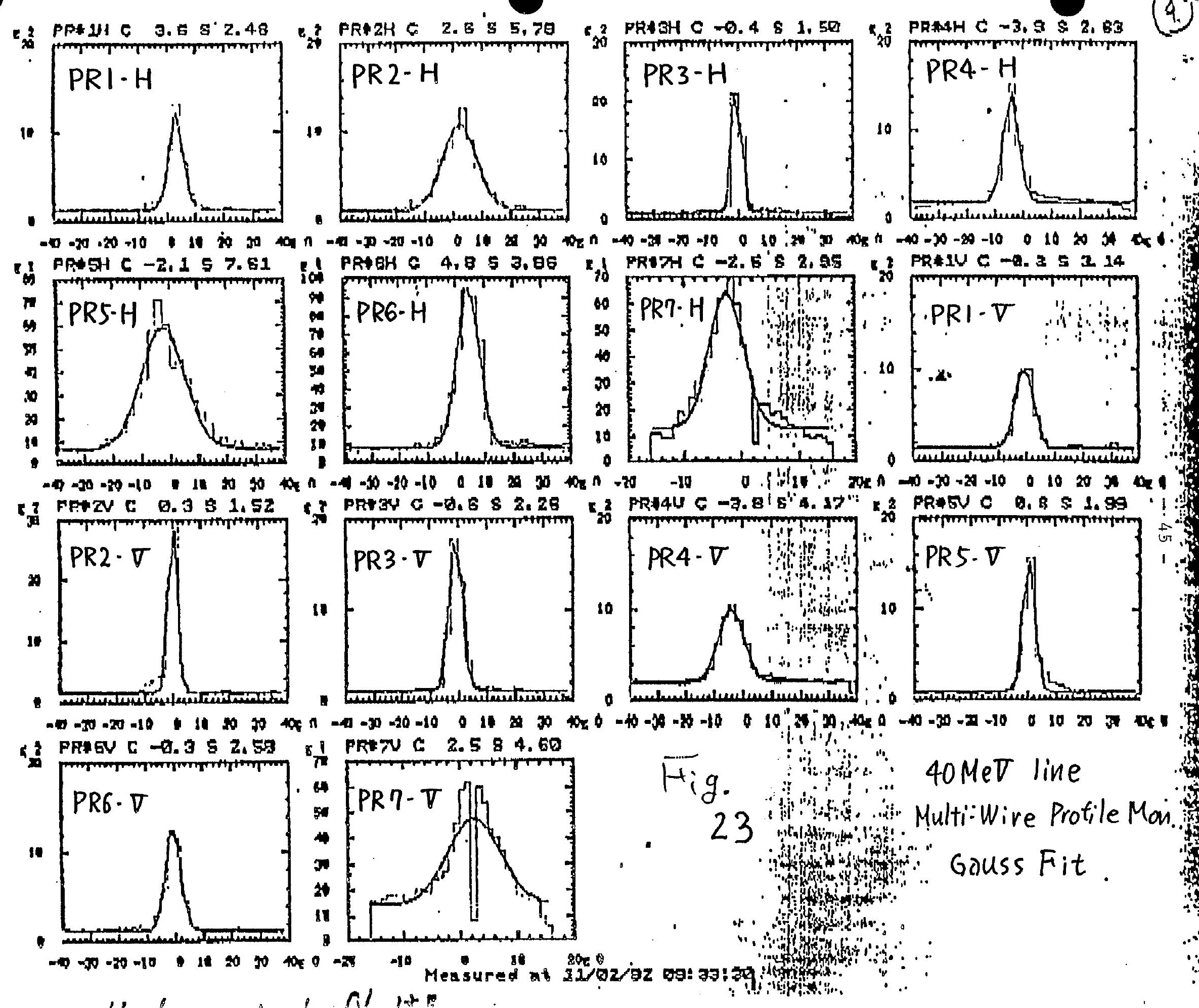



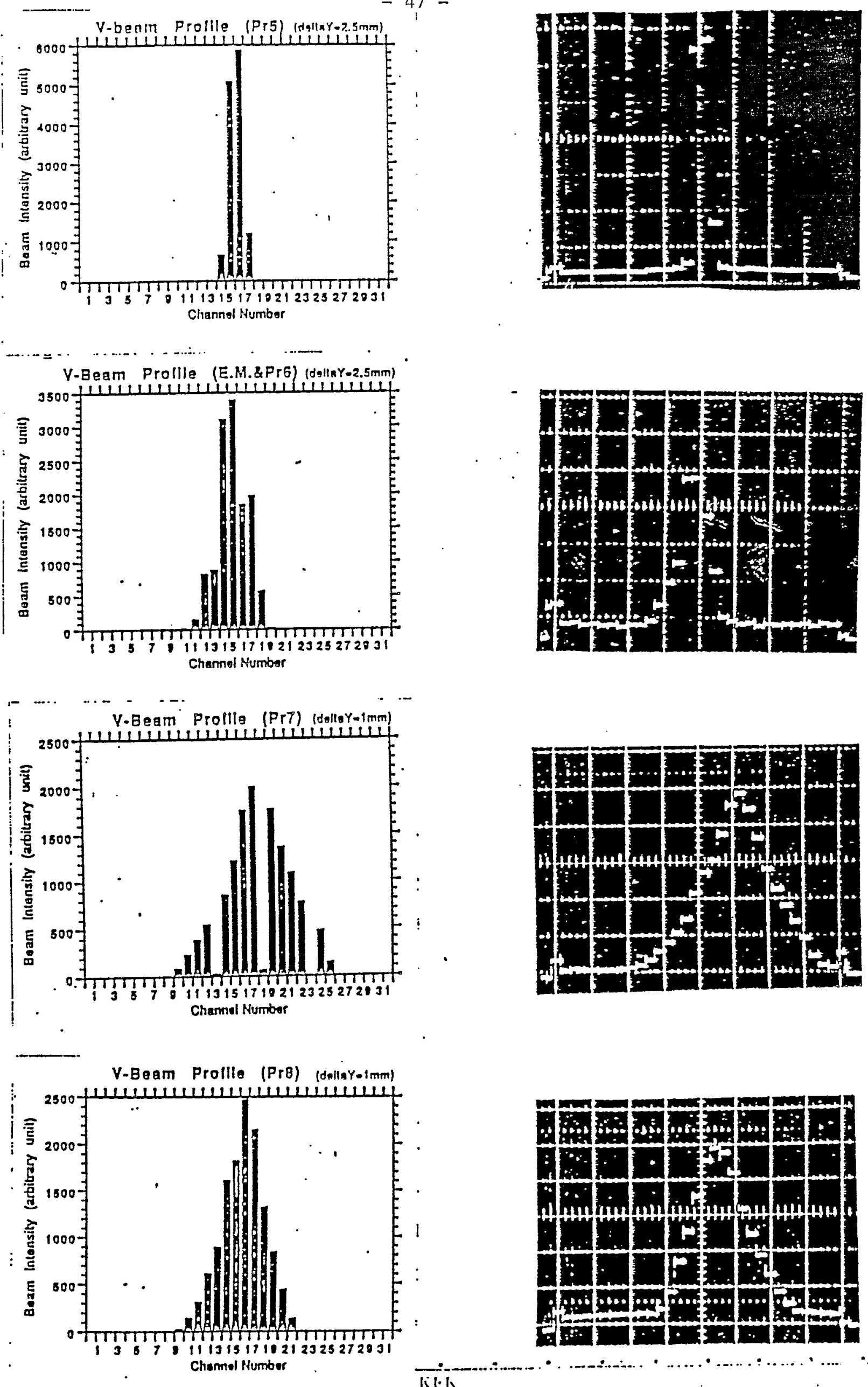

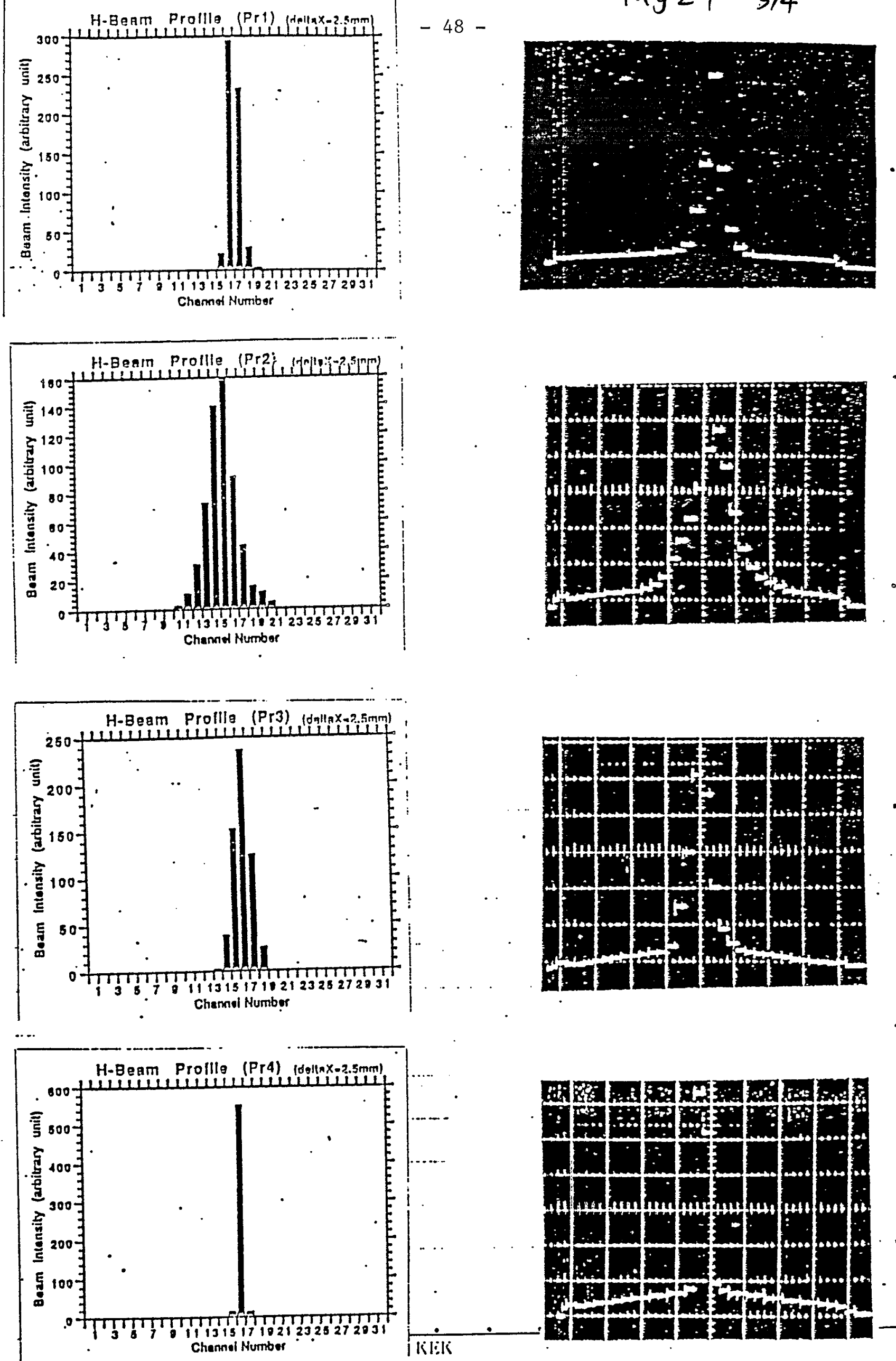

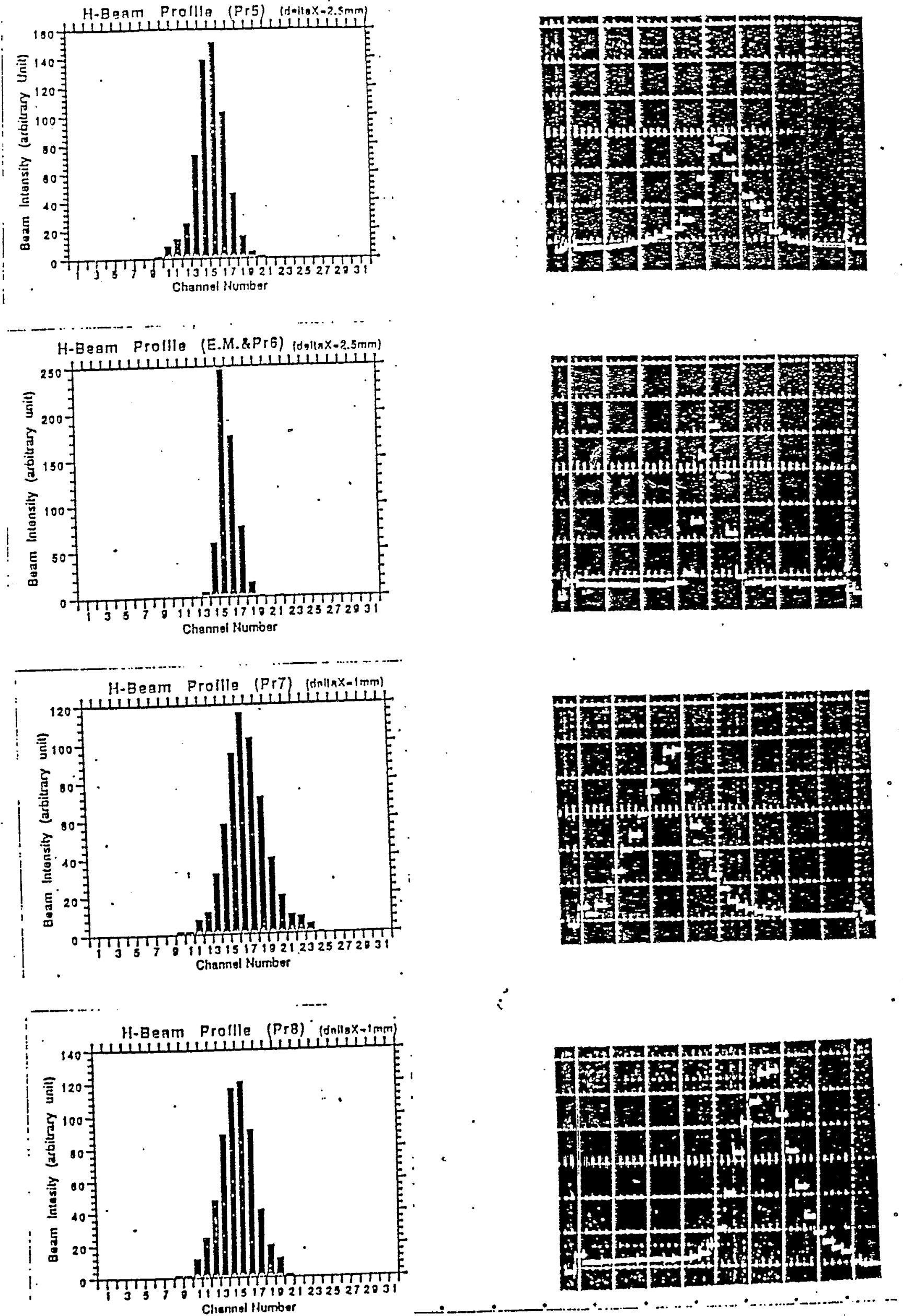
Before I close my presentation, I want to show you what the problems are at injection to the MR. I believe that they are also suggestive.

\section{Intensity Dependence of the Resonance Line}

Figure 25 shows the resonance lines at $\mathrm{Qh}=7.40$. The first data is about the resonance lines. This is the result of the vertical tune survey at $\mathrm{Qh}=7.4$. The beam is low intensity and de-bunched to a coasting beam. The resonance lines up to the 4th order are assigned as written below. But for the high intensity bunched beam, these resonances are connected and are deeper.

There is other data. Figure 26 shows the injection tune survey. We moved the tune from one point to another point to cross this resonance line $(\mathrm{Qh}-\mathrm{Qv}=0,2 \mathrm{Qh}-2 \mathrm{Qv}=0)$ and looked at the beam loss. This is like the work Kip Gardner did at the AGS Booster. There are no resonances lower than the 5th order along the path.

Figure 27 shows the resonance $\mathrm{Qh}=\mathrm{Qv}$. When the beam is coasting, the loss is small and sharp, but when the beam is bunched, the loss becomes deeper and broader. My expectation was that the beam loss would not change much, but would be three times slower (bunching factor $=3$ ). The resonances depend very much on the intensity or rf (bunched or unbunched). I think that we should first correct the resonance lines with low intensity, but we should remember that it will not be sufficient. 


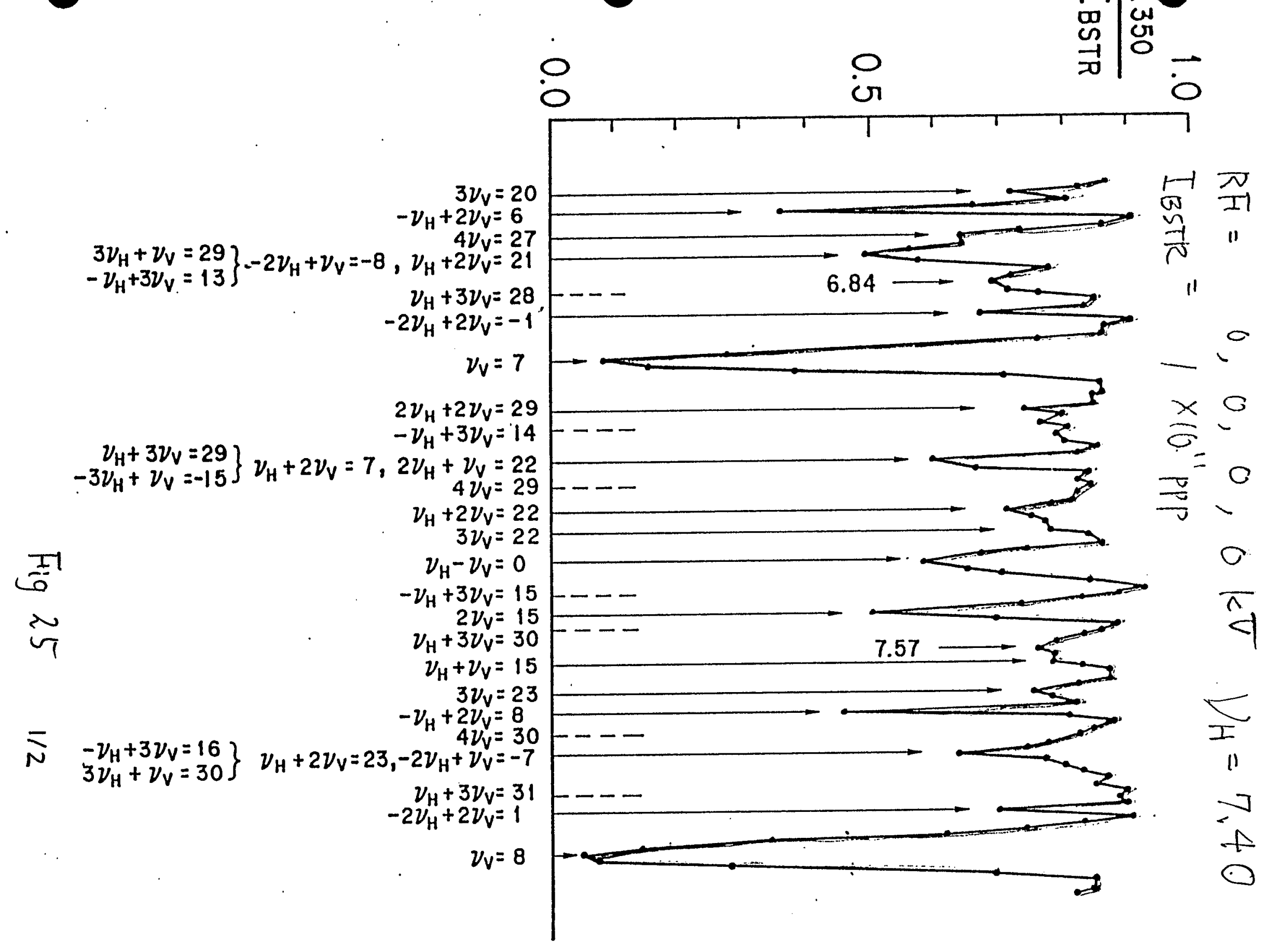




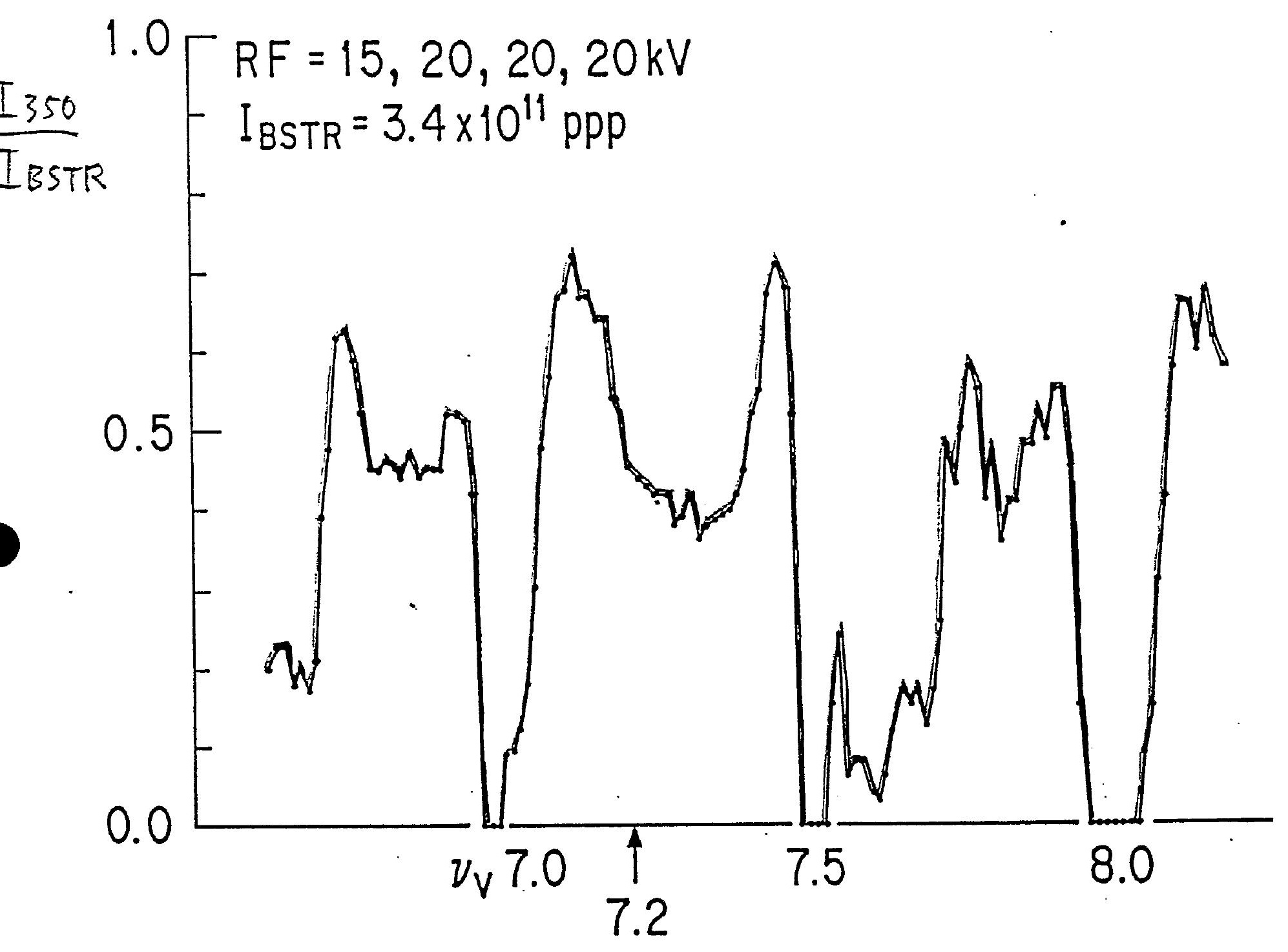

Fig $25 \quad 2 / 2$ 
$-53-$

194

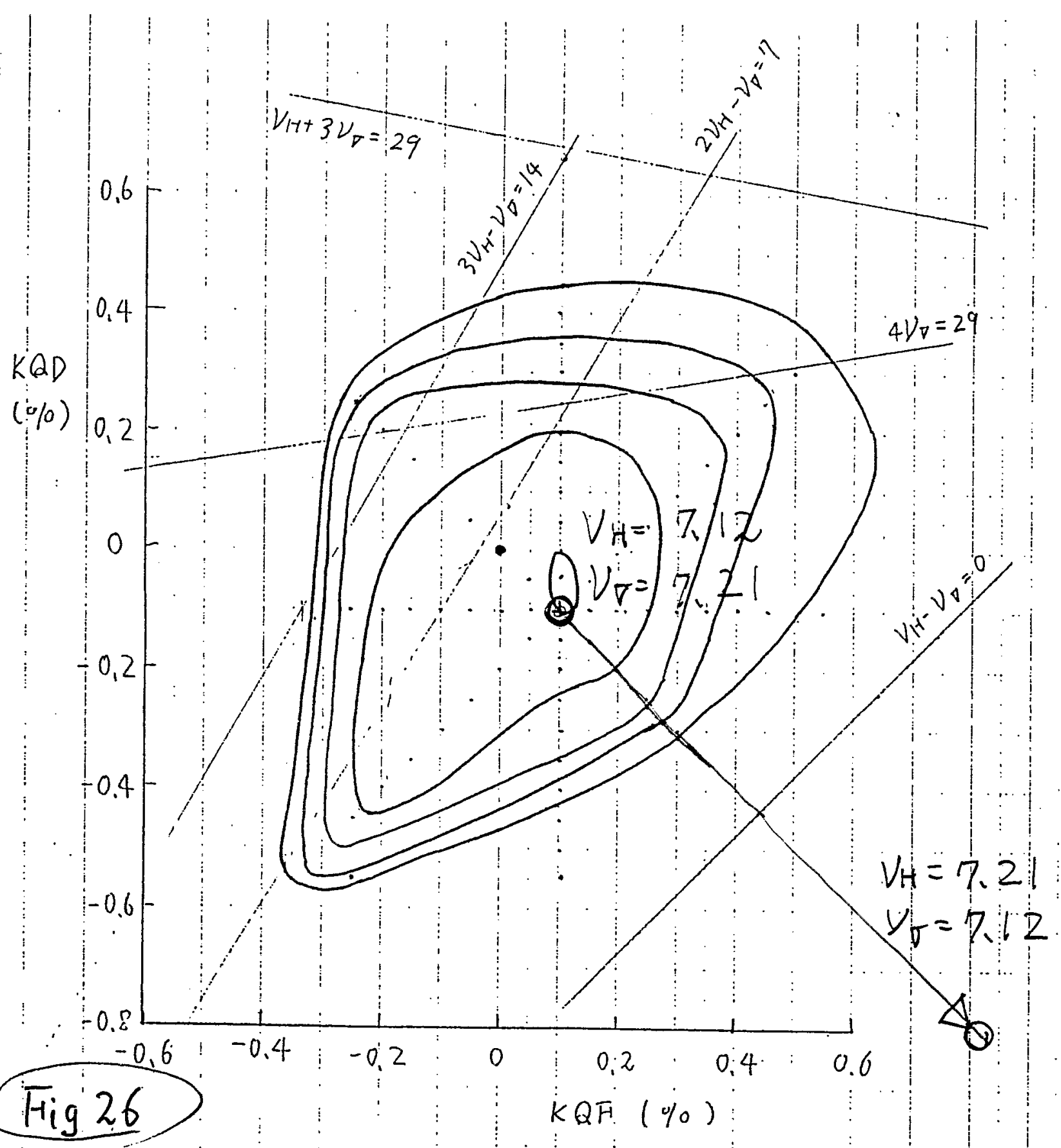

团 26 MR Injection Working Point 什近o tune survey

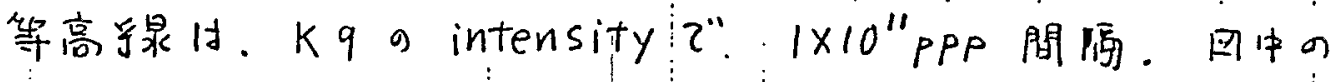
…1 remanent field on $2 \mathrm{~F}$.

Tune spread I. $\xi=-6$ とすると. $\Delta p / P= \pm 0.4 \%$ なので $\Delta V= \pm 0.17$ 


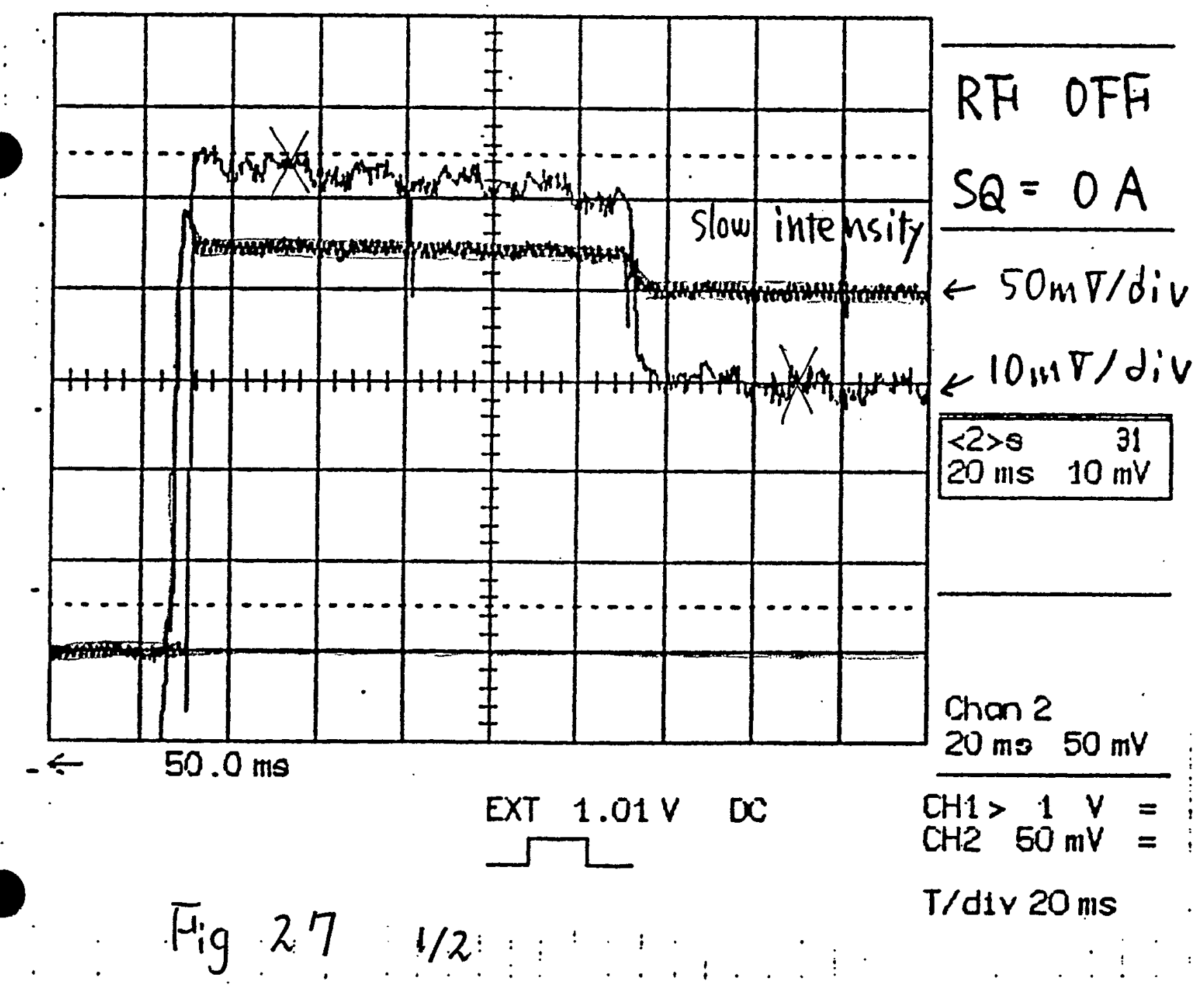




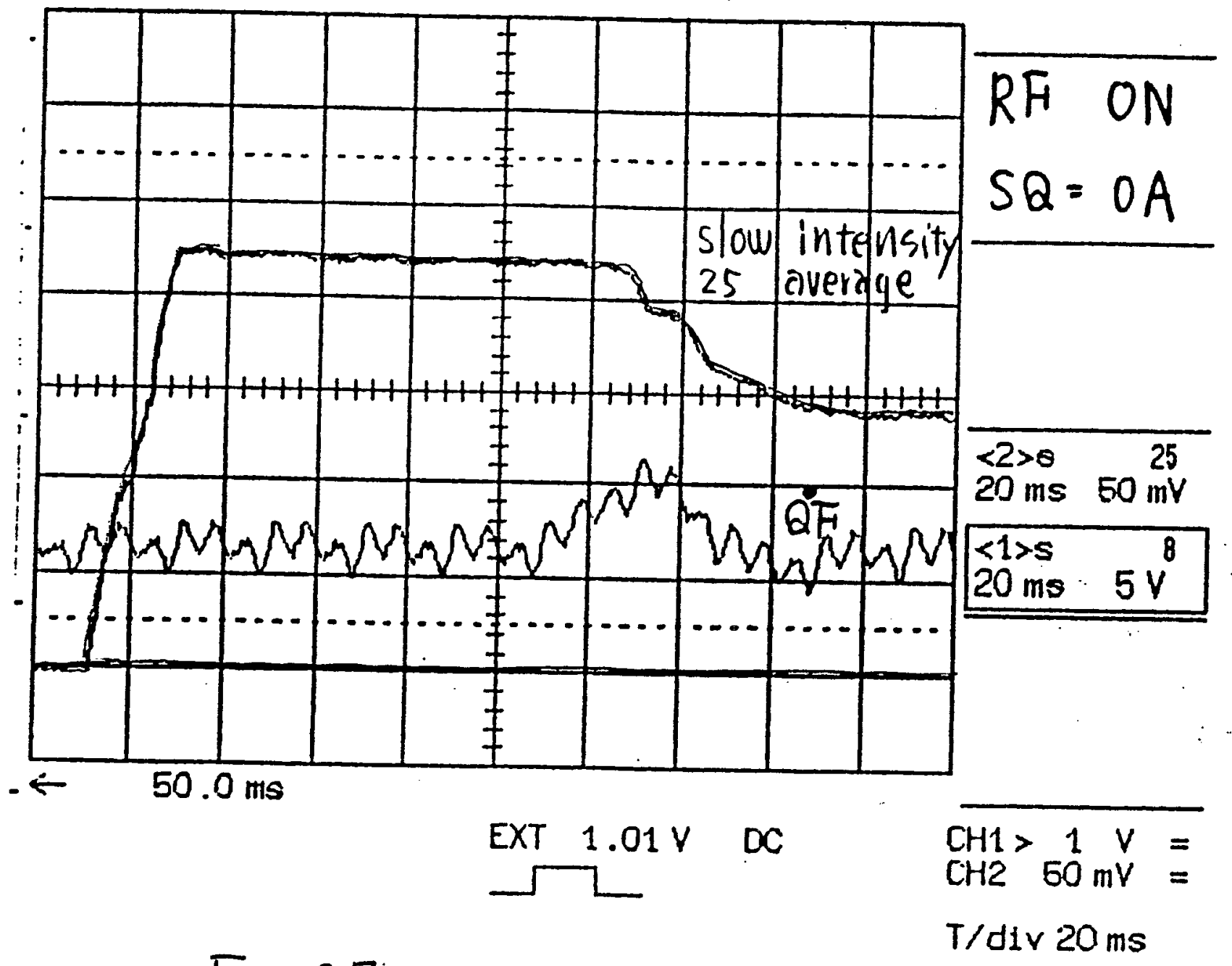

Fig $27 \quad 2 / 2$ 


\section{Coupled Bunch}

This is the vertical beam size in the MR measured by NDPM; the line is the number of particles. At this point we start acceleration, transition, and extraction.

Figure 28 shows the MR NDPM. The vertical beam size did not damp adiabatically. In this case, only the number of bunches was different. There are nine rf buckets in the main ring. At one beam size, all buckets were filled with protons. At another size, there were five proton-filed buckets and four vacant buckets. At another, only one bucket was filled with protons. The number of protons in one bucket was the same. The space charge effect was almost the same, but the beam sizes were much different. This is the evidence of the existence of some kind of coupled-bunch effect. 
- 57 -

$2=$

Time Dep. of Eegm Gize

06/1a'92 05

( normal beam)(Main 4-7D( U)

Gertical

(mii) Half Bean Wiath from BOTTOM to $20<\%$

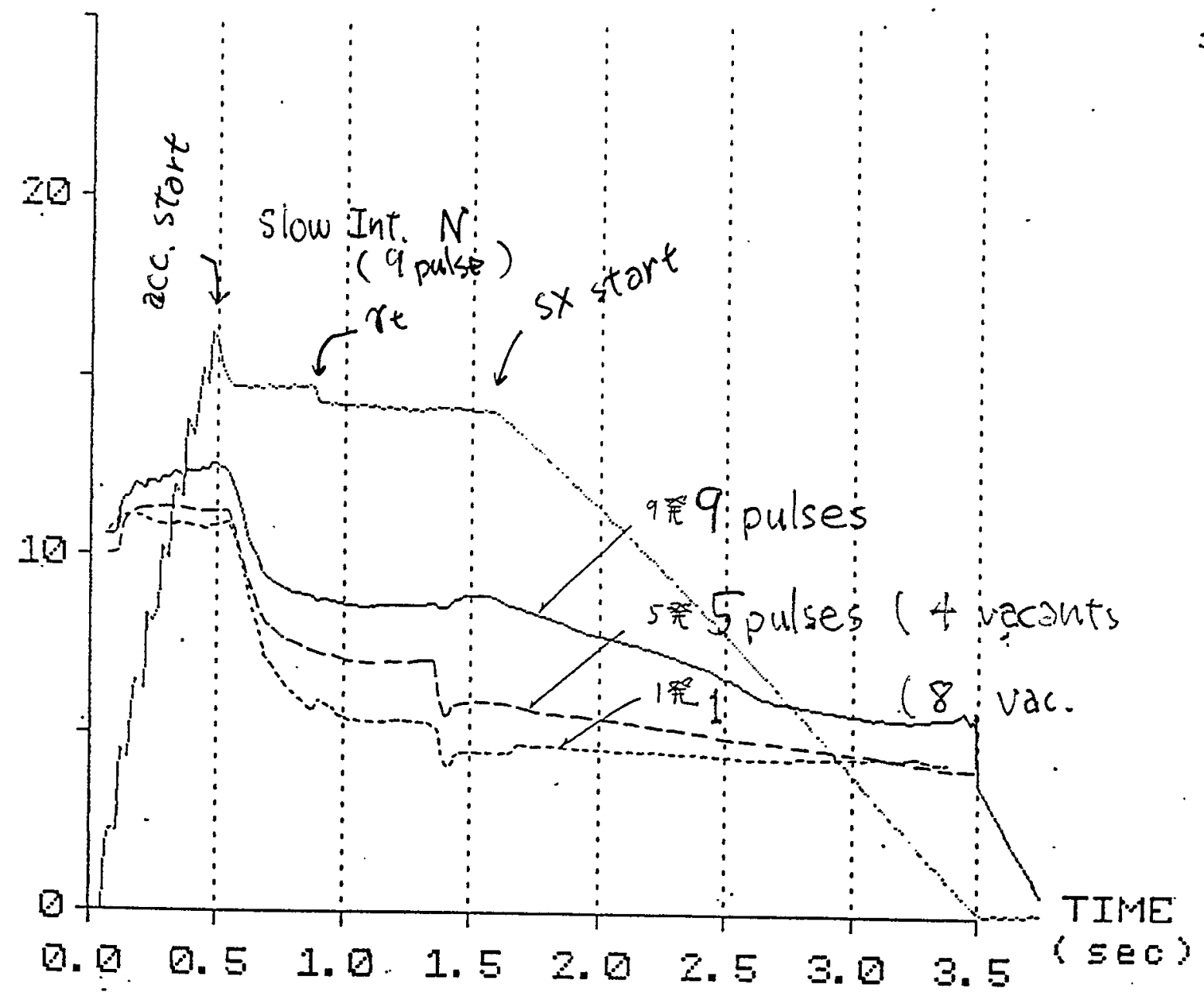

7.

Fig 28

国 14 Verticol beans size 'c Mir bunch 数 


\section{Edge Focus of the Bump Magnet}

Figure 29 shows the normal optics. This is the Twiss parameters of the KEK-Booster, but when the injection bump magnets are working it changes. Figure 30 shows the abnormal cell. The edge focus of the bump magnets changes the optics. We did not recognize such a big effect until last month (January, 1993). We then had to reconsider the matching conditions; we have not examined the results experimentally. It changed the optics, including the horizontal tune. It becomes as low as 2.09. I don't think it will reduce the space charge limit because the beam is captured in the rf bucket after the bump has disappeared. At this time, the bunching factor is 1 .

\section{Acknowledgements}

I thank the KEK-PS crew for their help. They send me updated data and we have continued our discussions long distance. I also thank my office-mate, Thomas Russo, who read this report and repaired my English. 
Fig 29

I. Yamane

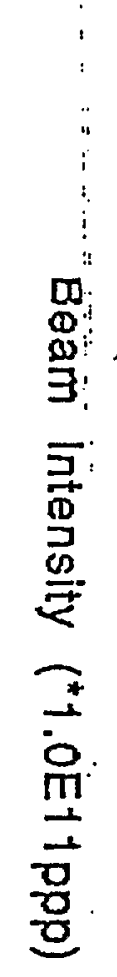

Normal Optics of Booster

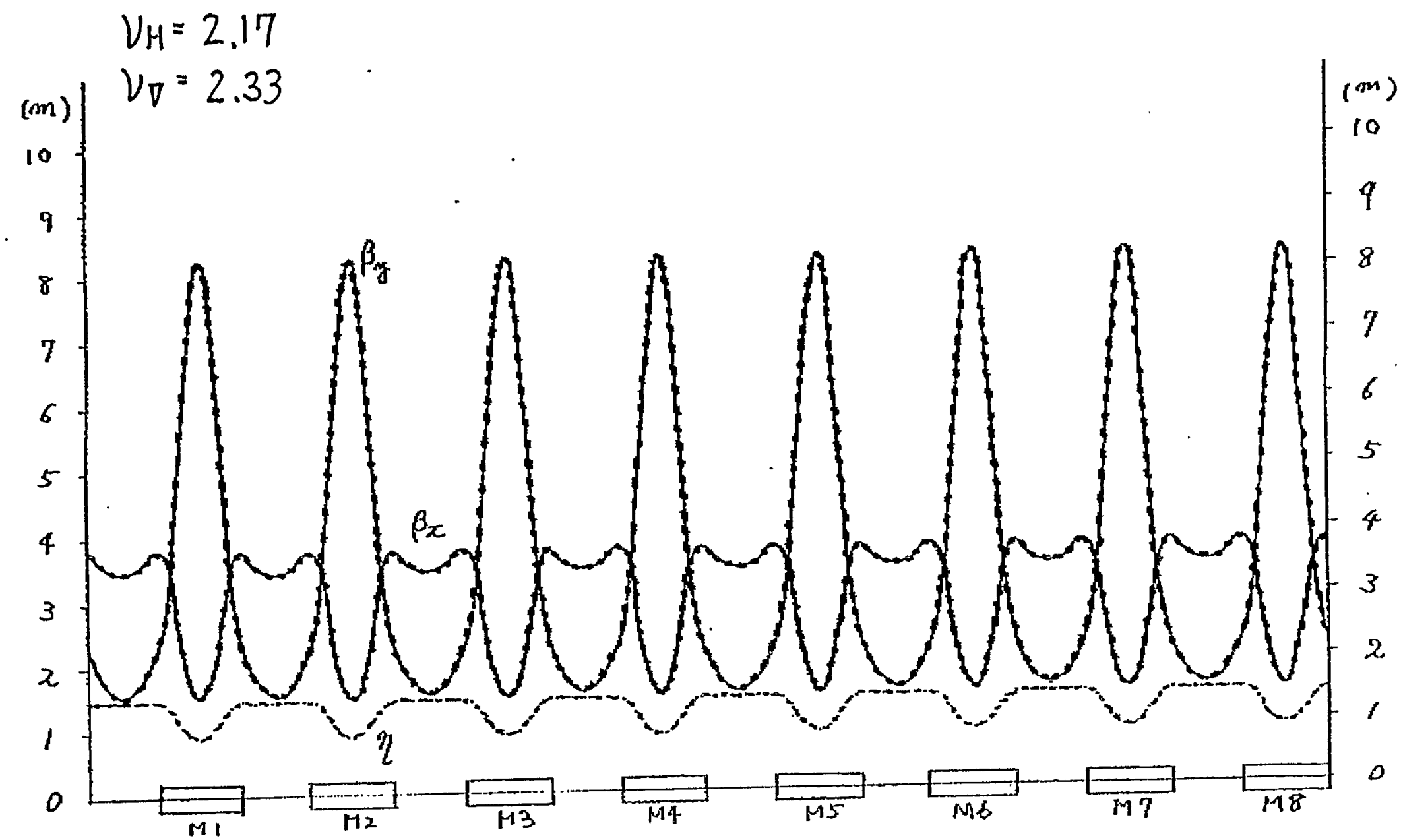


Fig. 30 Abnormal Optics of Booster due to ti Bump Magnets

$$
V_{H}=2.09
$$

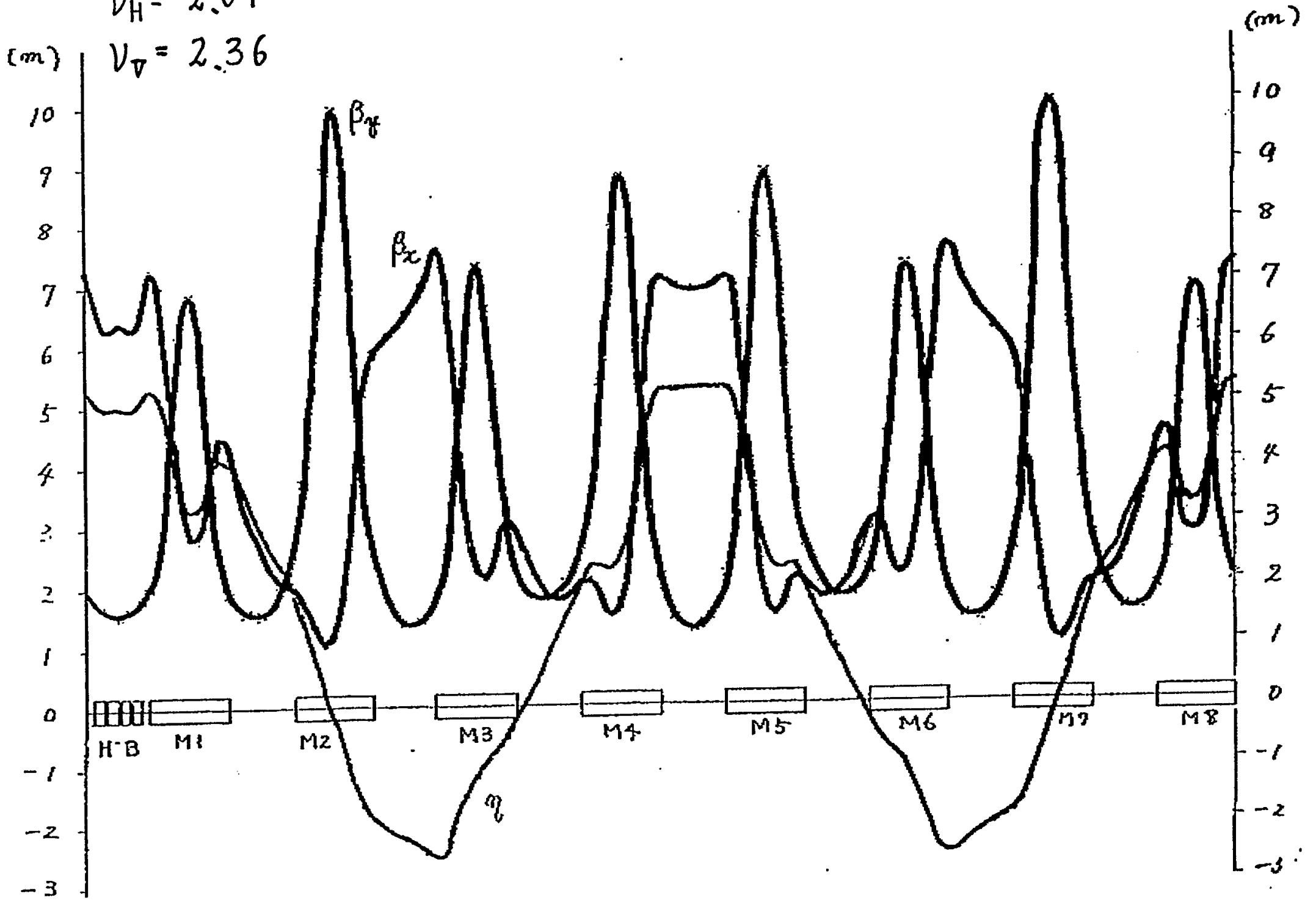

